\title{
Magnetohydrodynamic Three-Dimensional Couette Flow of a Maxwell Fluid with Periodic Injection/Suction
}

\author{
Y. Ali, ${ }^{1}$ M. A. Rana, ${ }^{1}$ and M. Shoaib ${ }^{2}$ \\ ${ }^{1}$ Department of Mathematics and Statistics, Riphah International University, Sector I-14, Islamabad, Pakistan \\ ${ }^{2}$ COMSATS Institute of Information Technology, Kamra Road, Attock 43600, Pakistan \\ Correspondence should be addressed to Y. Ali; ryasir5@gmail.com
}

Received 26 December 2016; Accepted 14 March 2017; Published 13 April 2017

Academic Editor: Eusebio Valero

Copyright (C) 2017 Y. Ali et al. This is an open access article distributed under the Creative Commons Attribution License, which permits unrestricted use, distribution, and reproduction in any medium, provided the original work is properly cited.

\begin{abstract}
A mathematical model for magnetohydrodynamic (MHD) three-dimensional Couette flow of an incompressible Maxwell fluid is developed and analyzed theoretically. The application of transverse sinusoidal injection at the lower stationary plate and its equivalent removal by suction through the uniformly moving upper plate lead to three-dimensional flow. Approximate solutions for velocity field, pressure, and skin friction are obtained. The effects of flow parameters such as Hartmann number, Reynolds number, suction/injection parameter, and the Deborah number on velocity components, skin friction factors along main flow direction and transverse direction, and pressure through parallel porous plates are discussed graphically. It is noted that Hartmann number provides a mechanism to control the skin friction component along the main flow direction.
\end{abstract}

\section{Introduction}

In recent years, the problem of LFC (laminar flow control) has gained considerable importance due to its importance in the reduction of drag and hence in improving the vehicle power by a considerable amount. To control the boundary layer artificially, several methods have been proposed. One of the effective techniques for the reduction of the drag coefficient which causes large energy losses is the boundary layer suction method. It has been established theoretically as well as experimentally that the laminarization of boundary layer over a profile reduces the drag and hence the vehicle power requirements by a very significant amount. According to boundary layer, suction method slowed that fluid particles in the boundary layer are removed through the holes and slits in the wall into the interior of the body and, therefore, the transition from laminar to turbulent flow causing increase of drag coefficient may be deferred or prevented [1]. Many workers have considered the numerous aspects of fluid flow problems with suction but most of these studies cope with two-dimensional flows only. Gersten and Gross [2] considered the viscous fluid and studied the effect of transverse sinusoidal suction velocity on flow with heat transfer over a porous wall. Singh [3] studied the effect of transpiration cooling in the presence of the transverse sinusoidal suction/injection velocity. Chaudhary et al. [4] analyzed three-dimensional Couette flow in the presence of transpiration cooling between the plates and reported the effects of suction/injection velocity on the flow field, skin friction, and heat transfer. Guria and Jana [5] investigated unsteady three-dimensional fluctuating Couette flow through porous plates with heat transfer and found that the main flow velocity decreases with increase in frequency parameter; however, the magnitude of the cross flow velocity increases with increase in frequency parameter. Sharma et al. [6] considered radiation effect in three-dimensional Couette flow with suction/injection on temperature distribution. Chauhan and Kumar [7] investigated heat transient effects in a three-dimensional Couette flow between partly filled channels by a porous material. Various workers [8-11] also investigated three-dimensional flow viscous fluid past a porous plate under different physical conditions. Many technological problems and natural phenomena are vulnerable to magnetohydrodynamic (MHD) analysis. In the design of heat exchangers and pumps and flow meters, thermal protection, control, and reentry, in space propulsion and so 
forth, MHD principle is used by engineers. It has been proven theoretically and experimentally that the transition from laminar to turbulent flow which causes the drag coefficient to increase may be prevented/delayed by suction of the fluid by the application of transverse magnetic field and by heat and mass transfer from the boundary layer to the wall. Das [12] studied three-dimensional MHD Couette flow of a viscous incompressible fluid with heat transfer through a porous plate and reported effects of constant suction and sinusoidal injection on the flow. Sharma and Chaudhary [13] presented MHD effect on viscous incompressible flow between two horizontal parallel porous plates and heat transfer with periodic injection/suction. It was observed that forward flow is developed in the region near the stationary plate, while backward flow is developed in the region near the moving plate. Goyal and Naraniya [14] analyzed theoretically threedimensional free convection Couette flow of a viscous incompressible fluid with transpiration cooling in the presence of transverse magnetic field. The static plate and the plate in uniform motion are subjected to transverse sinusoidal injection and uniform suction of the fluid. Recently, many workers [15-17] studied three-dimensional Couette flow of an incompressible fluid.

All the above studies have been performed in viscous fluid. Although the Navier-Stokes equations can cope with the flows of viscous fluids, these equations are inadequate to describe the characteristics of non-Newtonian fluids. Shoaib et al. [18-22] analyzed theoretically three-dimensional nonNewtonian fluids flow along an infinite plane with periodic suction.

However, to the best of the authors' knowledge, the application of transverse sinusoidal injection/suction velocity for the flow of a second-grade fluid between parallel plates has not appeared in the literature. Therefore, in the present work, magnetohydrodynamic three-dimensional Couette flow of a Maxwell fluid with periodic injection/suction is analyzed. A constant suction velocity at the wall leads to two-dimensional flow [2]; however, due to variation of suction velocity in transverse direction on wall, the problem becomes threedimensional. The solution of the problem is presented using regular perturbation technique. The results obtained are evaluated for various dimensionless parameters such as suction/injection parameter $\alpha$, the Deborah number $\beta$, Hartmann number $M$, and Reynolds number Re. The article is organized as follows: Section 2 presents description of the problem, Section 3 gives formulation of the problem, Section 4 approximates solutions, and Section 5 incorporates results and discussion, while Section 6 includes conclusion.

\section{Description of the Problem}

Consider steady three-dimensional fully developed laminar Couette flow of an incompressible electrically conducting Maxwell fluid between two parallel porous plates having separation " $h$ " between them. The $x^{*} z^{*}$-plane is taken along the lower plate and the $y^{*}$-axis perpendicular to the plates as shown in Figure 1. The magnetic field of uniform strength B

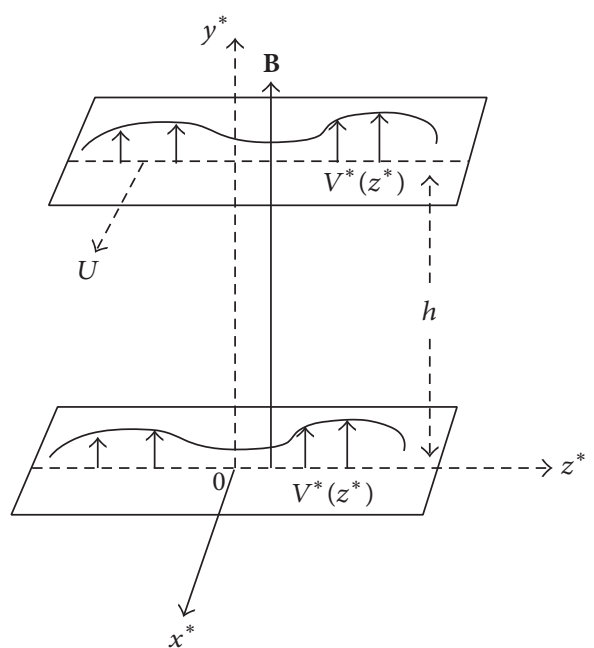

FIGURE 1: Diagram of the problem.

normal to the plates is applied. The injection/suction velocity distribution [2] of the form

$$
v^{*}\left(z^{*}\right)=v_{0}\left(1+\varepsilon \cos \pi \frac{z^{*}}{h}\right)
$$

is assumed, where $v_{0}$ is suction/injection velocity and $\varepsilon$ is its amplitude. The lower plate is kept stationary, while the upper plate is moving with uniform velocity $U$ along the positive $x^{*}$-axis. The transverse sinusoidal injection of the fluid at the lower plate with its corresponding removal by periodic suction through the upper plate is considered. The velocity components along the $x^{*}-, y^{*}$-, and $z^{*}$ - directions are $u^{*}, v^{*}$, and $w^{*}$, respectively. Since the flow is assumed to be fully developed and laminar, all the physical quantities are independent of $x^{*}$; of course, the flow remains threedimensional due to injection/suction velocity (1).

\section{Formulation of the Problem}

The constitutive equation for a Maxwell fluid model is

$$
\widetilde{T}=-p \widetilde{I}+\widetilde{S}
$$

where

$$
\widetilde{S}+\lambda \frac{D \widetilde{S}}{D t}=\mu \widetilde{A}_{1}, \quad \frac{D \widetilde{S}}{D t}=\frac{d \widetilde{S}}{d t}-\widetilde{L} \widetilde{S}-\widetilde{S} \widetilde{L}^{\mathrm{T}}
$$

in which $p, \lambda, \mu$, and $\widetilde{I}$ denote the pressure, relaxation time, the dynamic viscosity, and identity tensor, respectively; also $D / D t$ is the convective derivative. The Rivlin-Ericksen tensors $\widetilde{A}_{1}$ are defined as

$$
\widetilde{A}_{1}=\widetilde{L}+\widetilde{L}^{\mathrm{T}}, \quad \widetilde{L}=\operatorname{grad} \mathbf{V},
$$

where " $T$ " denotes the transpose. So model (2) is compatible with the thermodynamics in the sense that all the 
motions satisfy the Clausius-Duhen inequality and the specific Helmholtz free energy is minimum in equilibrium. The laws of conservation of mass and momentum are given by

$$
\begin{aligned}
\operatorname{div} \mathbf{V} & =0, \\
\rho \frac{\partial \mathbf{V}}{\partial t} & =\operatorname{div} \widetilde{T}+\mathbf{J} \times \mathbf{B} .
\end{aligned}
$$

Thus, the problem is governed by the following system of differential equations:

$$
\begin{aligned}
& \frac{\partial v^{*}}{\partial y^{*}}+\frac{\partial w^{*}}{\partial z^{*}}=0 \\
& \rho\left(v^{*} \frac{\partial u^{*}}{\partial y^{*}}+w^{*} \frac{\partial u^{*}}{\partial z^{*}}\right)+\lambda\left(v^{* 2} \frac{\partial^{2} u^{*}}{\partial y^{* 2}}+w^{* 2} \frac{\partial^{2} u^{*}}{\partial z^{* 2}}\right. \\
& \left.+2 v^{*} w^{*} \frac{\partial^{2} u^{*}}{\partial y^{*} \partial z^{*}}\right)=\mu\left(\frac{\partial^{2} u^{*}}{\partial y^{* 2}}+\frac{\partial^{2} u^{*}}{\partial z^{* 2}}\right)-\sigma B_{o}^{2}\left(u^{*}\right. \\
& -U)-\lambda\left(\frac{\partial u^{*}}{\partial y^{*}} \frac{\partial p^{*}}{\partial y^{*}}+\frac{\partial u^{*}}{\partial z^{*}} \frac{\partial p^{*}}{\partial z^{*}}\right), \\
& \rho\left(v^{*} \frac{\partial v^{*}}{\partial y^{*}}+w^{*} \frac{\partial v^{*}}{\partial z^{*}}\right)+\lambda\left(v^{* 2} \frac{\partial^{2} v^{*}}{\partial y^{* 2}}+w^{* 2} \frac{\partial^{2} v^{*}}{\partial z^{* 2}}\right. \\
& \left.+2 v^{*} w^{*} \frac{\partial^{2} v^{*}}{\partial y^{*} \partial z^{*}}\right)=-\frac{\partial p^{*}}{\partial y^{*}}+\mu\left(\frac{\partial^{2} v^{*}}{\partial y^{* 2}}+\frac{\partial^{2} v^{*}}{\partial z^{* 2}}\right) \\
& -\lambda\left(v^{*} \frac{\partial^{2} p^{*}}{\partial y^{* 2}}+w^{*} \frac{\partial^{2} p^{*}}{\partial y^{*} \partial z^{*}}-\frac{\partial v^{*}}{\partial y^{*}} \frac{\partial p^{*}}{\partial y^{*}}\right. \\
& \left.+\frac{\partial v^{*}}{\partial z^{*}} \frac{\partial p^{*}}{\partial z^{*}}\right) \\
& \rho\left(v^{*} \frac{\partial w^{*}}{\partial y^{*}}+w^{*} \frac{\partial w^{*}}{\partial z^{*}}\right)+\lambda\left(v^{* 2} \frac{\partial^{2} w^{*}}{\partial y^{* 2}}+w^{* 2} \frac{\partial^{2} w^{*}}{\partial z^{* 2}}\right. \\
& \left.+2 v^{*} w^{*} \frac{\partial^{2} w^{*}}{\partial y^{*} \partial z^{*}}\right)=-\frac{\partial p^{*}}{\partial z^{*}}+\mu\left(\frac{\partial^{2} w^{*}}{\partial y^{* 2}}+\frac{\partial^{2} w^{*}}{\partial z^{* 2}}\right) \\
& -\sigma B_{o}^{2} w^{*}-\lambda\left(v^{*} \frac{\partial^{2} p^{*}}{\partial y^{*} \partial z^{*}}+w^{*} \frac{\partial^{2} p^{*}}{\partial z^{* 2}}-\frac{\partial w^{*}}{\partial y^{*}} \frac{\partial p^{*}}{\partial y^{*}}\right. \\
& \left.+\frac{\partial w^{*}}{\partial z^{*}} \frac{\partial p^{*}}{\partial z^{*}}\right)
\end{aligned}
$$

subject to boundary conditions

$$
\begin{aligned}
u^{*} & =0, \\
v^{*}\left(z^{*}\right) & =v_{0}\left(1+\varepsilon \cos \pi \frac{z^{*}}{h}\right), \\
w^{*} & =0, \\
u^{*} & =U, \\
v^{*}\left(z^{*}\right) & =v_{0}\left(1+\varepsilon \cos \pi \frac{z^{*}}{h}\right), \\
w^{*} & =0 ;
\end{aligned}
$$$$
\text { at } y^{*}=h \text {. }
$$

The following dimensionless parameters have been introduced:

$$
\begin{aligned}
y & =\frac{y^{*}}{h}, \\
z & =\frac{z^{*}}{h}, \\
u & =\frac{u^{*}}{U}, \\
v & =\frac{v^{*}}{U}, \\
w & =\frac{w^{*}}{U}, \\
\alpha & =\frac{v_{o}}{U}, \\
\operatorname{Re} & =\frac{h U}{v}, \\
\beta & =\frac{\lambda U}{h}, \\
p & =\frac{p^{*}}{\rho U^{2}}, \\
M & =\sqrt{\frac{\sigma B_{o}^{2} h^{2}}{\rho v}},
\end{aligned}
$$

where $\alpha, \operatorname{Re}, \beta$, and $M$ denote suction/injection parameter, Reynolds number, the Deborah number, and Hartmann number, respectively. Then (6)-(7) become

$$
\begin{aligned}
& \frac{\partial v}{\partial y}+ \frac{\partial w}{\partial z}=0 \\
& v \frac{\partial u}{\partial y}+w \frac{\partial u}{\partial z}+\beta\left(v^{2} \frac{\partial^{2} u}{\partial y^{2}}+w^{2} \frac{\partial^{2} u}{\partial z^{2}}+2 v w \frac{\partial^{2} u}{\partial y \partial z}\right) \\
&=\frac{1}{\operatorname{Re}}\left(\frac{\partial^{2} u}{\partial y^{2}}+\frac{\partial^{2} u}{\partial z^{2}}-M^{2}(u-1)\right) \\
&-\beta\left(\frac{\partial u}{\partial y} \frac{\partial p}{\partial y}+\frac{\partial u}{\partial z} \frac{\partial p}{\partial z}\right) \\
& v \frac{\partial v}{\partial y}+w \frac{\partial v}{\partial z}+\beta\left(v^{2} \frac{\partial^{2} v}{\partial y^{2}}+w^{2} \frac{\partial^{2} v}{\partial z^{2}}+2 v w \frac{\partial^{2} v}{\partial y \partial z}\right) \\
&=-\frac{\partial p}{\partial y}+\frac{1}{\operatorname{Re}}\left(\frac{\partial^{2} v}{\partial y^{2}}+\frac{\partial^{2} v}{\partial z^{2}}\right) \\
& \quad-\beta\left(v \frac{\partial^{2} p}{\partial y^{2}}+w \frac{\partial^{2} p}{\partial y \partial z}-\frac{\partial v}{\partial y} \frac{\partial p}{\partial y}+\frac{\partial v}{\partial z} \frac{\partial p}{\partial z}\right)
\end{aligned}
$$




$$
\begin{aligned}
v \frac{\partial w}{\partial y} & +w \frac{\partial w}{\partial z}+\beta\left(v^{2} \frac{\partial^{2} w}{\partial y^{2}}+w^{2} \frac{\partial^{2} w}{\partial z^{2}}+2 v w \frac{\partial^{2} w}{\partial y \partial z}\right) \\
= & -\frac{\partial p}{\partial z}+\frac{1}{\operatorname{Re}}\left(\frac{\partial^{2} w}{\partial y^{2}}+\frac{\partial^{2} w}{\partial z^{2}}-M^{2} w\right) \\
& -\beta\left(v \frac{\partial^{2} p}{\partial y \partial z}+w \frac{\partial^{2} p}{\partial z^{2}}-\frac{\partial w}{\partial y} \frac{\partial p}{\partial y}+\frac{\partial w}{\partial z} \frac{\partial p}{\partial z}\right)
\end{aligned}
$$

subject to nondimensional boundary conditions

$$
\begin{aligned}
u & =0, \\
v(z) & =\alpha(1+\varepsilon \cos \pi z), \\
w & =0,
\end{aligned}
$$$$
\text { at } y=0 \text {; }
$$$$
u=1 \text {, }
$$

$$
\begin{aligned}
v(z) & =\alpha(1+\varepsilon \cos \pi z), \\
w & =0 ;
\end{aligned}
$$

$$
\text { at } y=1 \text {. }
$$

$u, v$, and $w$ denote the velocities in the $x_{-}, y_{-}$, and $z$ directions, respectively.

\section{Solution of the Problem}

4.1. Cross-Flow Solution. Since $\varepsilon \ll 1$ and is positive, we assume the solution of the form

$$
H(y, z)=H_{0}(y)+\varepsilon H_{1}(y, z)+\varepsilon^{2} H_{2}(y, z)+\cdots,
$$

where $H$ stands for any of $u, v, w$, and $p$. The set of cross-flow solutions $v_{1}(y, z), w_{1}(y, z)$, and $p_{1}(y, z)$ is independent of the main flow velocity component $u$. The equations governing the fluid flow are

$$
\begin{aligned}
& \frac{\partial v_{1}}{\partial y}+\frac{\partial w_{1}}{\partial z}=0 \\
& \alpha \frac{\partial v_{1}}{\partial y}+\beta \alpha^{2} \frac{\partial^{2} v_{1}}{\partial y^{2}} \\
& =-\frac{\partial p_{1}}{\partial y}-\beta \alpha \frac{\partial^{2} p_{1}}{\partial y^{2}}+\frac{1}{\operatorname{Re}}\left(\frac{\partial^{2} v_{1}}{\partial y^{2}}+\frac{\partial^{2} v_{1}}{\partial z^{2}}\right), \\
& \alpha \frac{\partial w_{1}}{\partial y}+\beta \alpha^{2} \frac{\partial^{2} w_{1}}{\partial y^{2}} \\
& =-\frac{\partial p_{1}}{\partial z}-\beta \alpha \frac{\partial^{2} p_{1}}{\partial y \partial z} \\
& \quad+\frac{1}{\operatorname{Re}}\left(\frac{\partial^{2} w_{1}}{\partial y^{2}}+\frac{\partial^{2} w_{1}}{\partial z^{2}}-M^{2} w_{1}\right) .
\end{aligned}
$$

And the boundary conditions are

$$
\begin{aligned}
& v_{1}(0, z)=\alpha \cos \pi z, \\
& w_{1}(0, z)=0, \\
& v_{1}(1, z)=\alpha \cos \pi z, \\
& w_{1}(1, z)=0 .
\end{aligned}
$$

The injection/suction velocity consists of basic uniform distribution $v_{o}$ with a superimposed weak sinusoidal distribution $\varepsilon v_{o} \cos \pi z$; therefore the velocity components $v_{1}(y, z)$, $w_{1}(y, z)$, and pressure component $p_{1}(y, z)$ are also separated into main and small sinusoidal components. Hence, we assume that

$$
\begin{aligned}
& v_{1}(y, z)=v_{11}(y) \cos \pi z, \\
& w_{1}(y, z)=-\frac{1}{\pi} v_{11}^{\prime} \sin \pi z, \\
& p_{1}(y, z)=p_{11}(y) \cos \pi z .
\end{aligned}
$$

Here ", " denotes the differentiation with respect to " $y$." It is worth mentioning that the velocity components (19)-(20) identically satisfy the continuity equation (15). Set (18)-(20) into (16) and (17) to have

$$
\begin{aligned}
\alpha v_{11}^{\prime}+\beta \alpha^{2} v_{11}^{\prime \prime}= & -p_{11}^{\prime}-\beta \alpha p_{11}^{\prime \prime}+\frac{1}{\mathrm{Re}}\left(v_{11}^{\prime \prime}-\pi^{2} v_{11}\right), \\
\alpha v_{11}^{\prime \prime}+\beta \alpha^{2} v_{11}^{\prime \prime \prime}= & -\pi^{2} p_{11}-\beta \alpha \pi^{2} p_{11}^{\prime} \\
& +\frac{1}{\operatorname{Re}}\left(v_{11}^{\prime \prime \prime}-\left(\pi^{2}+M^{2}\right) v_{11}^{\prime}\right) .
\end{aligned}
$$

Eliminate the pressure $p_{11}$ from (22) and (23) to get

$$
\begin{aligned}
v_{11}^{\prime v} & +\pi^{4} v_{11}-2 \pi^{2} v_{11}^{\prime \prime}-M^{2} v_{11}^{\prime \prime}-R\left(v_{11}^{\prime \prime \prime}-\pi^{2} v_{11}^{\prime}\right) \\
& =\beta \alpha^{2} \operatorname{Re}\left(v_{11}^{\prime v}-\pi^{2} v_{11}^{\prime \prime}\right),
\end{aligned}
$$

where $\alpha \operatorname{Re}=R$. Assuming that $\beta \ll 1$ and taking

$$
v_{11}(y)=v_{110}(y)+\beta v_{111}(y)+O\left(\beta^{2}\right),
$$

(24) becomes

$$
\begin{aligned}
& v_{110}^{\prime v}+\pi^{4} v_{110}-2 \pi^{2} v_{110}^{\prime \prime}-M^{2} v_{110}^{\prime \prime}-R\left(v_{110}^{\prime \prime \prime}-\pi^{2} v_{110}^{\prime}\right) \\
& =0
\end{aligned}
$$

The corresponding boundary conditions are

$$
\begin{aligned}
& v_{110}(0)=\alpha=v_{110}(1), \\
& v_{110}^{\prime}(0)=0=v_{110}^{\prime}(1) .
\end{aligned}
$$

In view of boundary conditions (27), the general solution of (26) yields

$$
v_{110}(y)=L_{7} e^{L_{3} y}+L_{8} e^{L_{4} y}+L_{9} e^{L_{5} y}+L_{10} e^{L_{6} y} .
$$


Similarly, the first-order equation is

$$
\begin{aligned}
v_{111}^{\prime v} & +\pi^{4} v_{111}-2 \pi^{2} v_{111}^{\prime \prime}-M^{2} v_{111}^{\prime \prime}-R\left(v_{111}^{\prime \prime \prime}-\pi^{2} v_{111}^{\prime}\right) \\
& =\alpha R\left(v_{110}^{\prime v}-\pi^{2} v_{110}^{\prime \prime}\right) .
\end{aligned}
$$

And corresponding boundary conditions are

$$
\begin{aligned}
& v_{111}(0)=0, \\
& v_{111}(1)=0, \\
& v_{111}^{\prime}(0)=0, \\
& v_{111}^{\prime}(1)=0 .
\end{aligned}
$$

The solution of the boundary value problem (29)-(30) is

$$
\begin{aligned}
& v_{111}(y) \\
& =L_{11} e^{L_{3} y}+L_{12} e^{L_{4} y}+L_{13} e^{L_{5} y}+L_{14} e^{L_{6} y} \\
& \quad+y\left(L_{15} e^{L_{3} y}+L_{16} e^{L_{4} y}+L_{17} e^{L_{5} y}+L_{18} e^{L_{6} y}\right) .
\end{aligned}
$$

Thus, (25), (19), and (20) after substituting (28) and (31), respectively, become

$$
\begin{aligned}
& v_{11}(y)=L_{7} e^{L_{3} y}+L_{8} e^{L_{4} y}+L_{9} e^{L_{5} y}+L_{10} e^{L_{6} y} \\
& +\beta\left(L_{11} e^{L_{3} y}+L_{12} e^{L_{4} y}+L_{13} e^{L_{5} y}+L_{14} e^{L_{6} y}\right. \\
& \left.+y\left(L_{15} e^{L_{3} y}+L_{16} e^{L_{4} y}+L_{17} e^{L_{5} y}+L_{18} e^{L_{6} y}\right)\right) \\
& v_{1}(y, z)=\left(L_{7} e^{L_{3} y}+L_{8} e^{L_{4} y}+L_{9} e^{L_{5} y}+L_{10} e^{L_{6} y}\right. \\
& +\beta\left(L_{11} e^{L_{3} y}+L_{12} e^{L_{4} y}+L_{13} e^{L_{5} y}+L_{14} e^{L_{6} y}\right. \\
& \left.\left.+y\left(L_{15} e^{L_{3} y}+L_{16} e^{L_{4} y}+L_{17} e^{L_{5} y}+L_{18} e^{L_{6} y}\right)\right)\right) \\
& +\cos \pi z, \\
& w_{1}(y, z)=-\frac{1}{\pi}\left(L_{7} L_{3} e^{L_{3} y}+L_{8} L_{4} e^{L_{4} y}+L_{9} L_{5} e^{L_{5} y}\right. \\
& +L_{10} L_{6} e^{L_{6} y}+\beta\left(L_{11} L_{3} e^{L_{3} y}+L_{12} L_{4} e^{L_{4} y}\right. \\
& +L_{13} L_{5} e^{L_{5} y}+L_{14} L_{6} e^{L_{6} y}+L_{15} e^{L_{3} y}+L_{16} e^{L_{4} y} \\
& +L_{17} e^{L_{5} y}+L_{18} e^{L_{6} y}+y\left(L_{15} L_{3} e^{L_{3} y}+L_{16} L_{4} e^{L_{4} y}\right. \\
& \left.\left.\left.+L_{17} L_{5} e^{L_{5} y}+L_{18} L_{6} e^{L_{6} y}\right)\right)\right) \sin \pi z
\end{aligned}
$$

where constants $L_{i}(i=1,2,3, \ldots, 18)$ are defined in the Appendix.

4.2. Pressure. Substituting (32) in (23), we have

$$
\begin{gathered}
p_{11}(y)=L_{19} e^{L_{3} y}+L_{20} e^{L_{4} y}+L_{21} e^{L_{5} y}+L_{22} e^{L_{6} y} \\
+\beta\left(L_{23} e^{L_{3} y}+L_{24} e^{L_{4} y}+L_{25} e^{L_{5} y}+L_{26} e^{L_{6} y}\right. \\
\left.+y\left(L_{27} e^{L_{3} y}+L_{28} e^{L_{4} y}+L_{29} e^{L_{5} y}+L_{30} e^{L_{6} y}\right)\right) .
\end{gathered}
$$

4.2.1. Main Flow Solution. When $\varepsilon=0$, the problem is reduced to two-dimensional flow, and we have

$$
\frac{d^{2} u_{0}}{d y^{2}}-M^{2}\left(u_{0}-1\right)=R \frac{d u_{0}}{d y}+\beta \alpha R \frac{d^{2} u_{0}}{d y^{2}},
$$

and corresponding boundary conditions are

$$
\begin{aligned}
& u_{0}(0)=0, \\
& u_{0}(1)=1,
\end{aligned}
$$

since $\beta \ll 1$, so we assume that

$$
u_{0}=u_{00}+\beta u_{01}+O\left(\beta^{2}\right)
$$

Then,

$$
\begin{aligned}
\frac{d^{2} u_{00}}{d y^{2}}-R \frac{d u_{00}}{d y}-M^{2}\left(u_{00}-1\right) & =0, \\
u_{00}(0) & =0, \\
u_{00}(1) & =1 ;
\end{aligned}
$$

the solution of problem (39) is

$$
u_{00}(y)=1+\frac{e^{L_{1}+L_{2} y}-e^{L_{2}+L_{1} y}}{e^{L_{2}}-e^{L_{1}}} .
$$

Similarly, solution of the first-order boundary value problem,

$$
\begin{aligned}
\frac{d^{2} u_{01}}{d y^{2}}-R \frac{d u_{01}}{d y}-M^{2} u_{01} & =\alpha R \frac{d^{2} u_{00}}{d y^{2}}, \\
u_{01}(0) & =0 \\
u_{01}(1) & =0
\end{aligned}
$$

is

$$
\begin{aligned}
u_{01}(y)= & L_{31} e^{L_{1} y}+L_{32} e^{L_{2} y} \\
& +y\left(L_{33} e^{L_{1}+L_{2} y}+L_{34} e^{L_{2}+L_{1} y}\right) .
\end{aligned}
$$

Thus,

$$
\begin{gathered}
u_{0}(y)=1+\frac{e^{L_{1}+L_{2} y}-e^{L_{2}+L_{1} y}}{e^{L_{2}}-e^{L_{1}}}+\beta\left(L_{31} e^{L_{1} y}\right. \\
\left.+L_{32} e^{L_{2} y}+y\left(L_{33} e^{L_{1}+L_{2} y}+L_{34} e^{L_{2}+L_{1} y}\right)\right) .
\end{gathered}
$$

When $\varepsilon \neq 0$, the equations of motion governing the flow are perturbed by substituting (14) in (10) and (13); we have the first-order equation and corresponding boundary conditions. Then the first-order equation and corresponding boundary conditions are

$$
\begin{gathered}
\alpha \frac{\partial u_{1}}{\partial y}+v_{1} \frac{d u_{0}}{d y}+\beta\left(\alpha^{2} \frac{\partial^{2} u_{1}}{\partial y^{2}}+2 \alpha v_{1} \frac{d^{2} u_{0}}{d y^{2}}\right) \\
=\frac{1}{\operatorname{Re}}\left(\frac{\partial^{2} u_{1}}{\partial y^{2}}+\frac{\partial^{2} u_{1}}{\partial z^{2}}\right)-\beta \frac{d u_{0}}{d y} \frac{\partial p_{1}}{\partial y}, \\
u_{1}(0, z)=0=u_{1}(1, z) .
\end{gathered}
$$


The solution of (44) can be expressed as $u_{1}(y, z)=$ $u_{11}(y) \cos \pi z$. Then

$$
\begin{aligned}
& \frac{d^{2} u_{11}}{d y^{2}}-\pi^{2} u_{11}-R \frac{d u_{11}}{d y} \\
& =\operatorname{Re} v_{11} \frac{d u_{0}}{d y} \\
& \quad+\beta\left(\alpha R \frac{d^{2} u_{11}}{d y^{2}}+2 R v_{11} \frac{d^{2} u_{0}}{d y^{2}}+\operatorname{Re} \frac{d u_{0}}{d y} \frac{d p_{11}}{d y}\right) .
\end{aligned}
$$

The corresponding boundary conditions (45) become

$$
u_{11}(0)=0=u_{11}(1)
$$

Equation (46) is of third order, while we have only two conditions. To overcome this difficulty, we express the solution of (46) as follows:

$$
u_{11}(y)=u_{110}(y)+\beta u_{111}(y)+O\left(\beta^{2}\right)
$$

Then zeroth-order problem yields

$$
\begin{aligned}
\frac{d^{2} u_{110}}{d y^{2}}-R \frac{d u_{110}}{d y}-\left(\pi^{2}+M^{2}\right) u_{110} & =\operatorname{Re} v_{110} \frac{d u_{00}}{d y} \\
u_{110}(0) & =0=u_{110}(1) .
\end{aligned}
$$

The solution of problem (49) is

$$
\begin{aligned}
u_{110}(y)= & L_{37} e^{L_{35} y}+L_{38} e^{L_{36} y}+L_{39} e^{\left(L_{2}+L_{3}\right) y} \\
& -L_{40} e^{\left(L_{1}+L_{3}\right) y}+L_{41} e^{\left(L_{2}+L_{4}\right) y} \\
& -L_{42} e^{\left(L_{1}+L_{4}\right) y}+L_{43} e^{\left(L_{2}+L_{5}\right) y} \\
& -L_{44} e^{\left(L_{1}+L_{5}\right) y}+L_{45} e^{\left(L_{2}+L_{6}\right) y} \\
& -L_{46} e^{\left(L_{1}+L_{6}\right) y} .
\end{aligned}
$$

Similarly, the first-order problem and corresponding boundary conditions are

$$
\begin{aligned}
& \frac{d^{2} u_{111}}{d y^{2}}-R \frac{d u_{111}}{d y}-\left(\pi^{2}+M^{2}\right) u_{111} \\
& =\operatorname{Re}\left(v_{110}\left(\frac{d u_{01}}{d y}+2 \alpha \frac{d^{2} u_{00}}{d y^{2}}\right)\right. \\
& \left.+\frac{d u_{00}}{d y}\left(v_{111}+\frac{d p_{110}}{d y}\right)+\alpha^{2} \frac{d^{2} u_{00}}{d y^{2}}\right), \\
& u_{111}(0)=0, \\
& u_{111}(1)=0,
\end{aligned}
$$

and hence

$$
\begin{aligned}
& u_{111}(y)=L_{55} e^{L_{35} y}+L_{56} e^{L_{36} y}+\frac{L_{57}}{L_{35}-L_{36}} y e^{L_{35} y} \\
& +\frac{L_{58}}{L_{36}-L_{35}} y e^{L_{36} y}+\frac{L_{59}}{L_{47}} e^{\left(L_{2}+L_{3}\right) y} \\
& +\frac{L_{60}}{L_{48}} e^{\left(L_{1}+L_{3}\right) y}+\frac{L_{61}}{L_{49}} e^{\left(L_{2}+L_{4}\right) y} \\
& +\frac{L_{62}}{L_{50}} e^{\left(L_{1}+L_{4}\right) y}+\frac{L_{63}}{L_{51}} e^{\left(L_{2}+L_{5}\right) y} \\
& +\frac{L_{64}}{L_{52}} e^{\left(L_{1}+L_{5}\right) y}+\frac{L_{65}}{L_{53}} e^{\left(L_{2}+L_{6}\right) y} \\
& +\frac{L_{66}}{L_{54}} e^{\left(L_{1}+L_{6}\right) y} \\
& +\frac{L_{67}}{L_{47}}\left(y-\frac{2\left(L_{2}+L_{3}\right)-R}{L_{47}}\right) e^{\left(L_{2}+L_{3}\right) y} \\
& +\frac{L_{68}}{L_{48}}\left(y-\frac{2\left(L_{1}+L_{3}\right)-R}{L_{48}}\right) e^{\left(L_{1}+L_{3}\right) y} \\
& +\frac{L_{69}}{L_{49}}\left(y-\frac{2\left(L_{2}+L_{4}\right)-R}{L_{49}}\right) e^{\left(L_{2}+L_{4}\right) y} \\
& +\frac{L_{70}}{L_{50}}\left(y-\frac{2\left(L_{1}+L_{4}\right)-R}{L_{50}}\right) e^{\left(L_{1}+L_{4}\right) y} \\
& +\frac{L_{71}}{L_{51}}\left(y-\frac{2\left(L_{2}+L_{5}\right)-R}{L_{51}}\right) e^{\left(L_{2}+L_{5}\right) y} \\
& +\frac{L_{72}}{L_{52}}\left(y-\frac{2\left(L_{1}+L_{5}\right)-R}{L_{52}}\right) e^{\left(L_{1}+L_{5}\right) y} \\
& +\frac{L_{73}}{L_{53}}\left(y-\frac{2\left(L_{2}+L_{6}\right)-R}{L_{53}}\right) e^{\left(L_{2}+L_{6}\right) y} \\
& +\frac{L_{74}}{L_{54}}\left(y-\frac{2\left(L_{1}+L_{6}\right)-R}{L_{54}}\right) e^{\left(L_{1}+L_{6}\right) y} .
\end{aligned}
$$

In view of (43), (50), (52), and (48) to (14), one has

$$
\begin{aligned}
& u(y, z)=1+\frac{e^{L_{1}+L_{2} y}-e^{L_{2}+L_{1} y}}{e^{L_{2}}-e^{L_{1}}}+\beta\left(L_{31} e^{L_{1} y}\right. \\
& \left.+L_{32} e^{L_{2} y}+y\left(L_{33} e^{L_{1}+L_{2} y}+L_{34} e^{L_{2}+L_{1} y}\right)\right) \\
& +\varepsilon\left(L_{37} e^{L_{35} y}+L_{38} e^{L_{36} y}+L_{39} e^{\left(L_{2}+L_{3}\right) y}\right. \\
& -L_{40} e^{\left(L_{1}+L_{3}\right) y}+L_{41} e^{\left(L_{2}+L_{4}\right) y}-L_{42} e^{\left(L_{1}+L_{4}\right) y} \\
& +L_{43} e^{\left(L_{2}+L_{5}\right) y}-L_{44} e^{\left(L_{1}+L_{5}\right) y}+L_{45} e^{\left(L_{2}+L_{6}\right) y} \\
& -L_{46} e^{\left(L_{1}+L_{6}\right) y}+\beta\left(L_{55} e^{L_{35} y}+L_{56} e^{L_{36} y}\right.
\end{aligned}
$$




$$
\begin{aligned}
+ & \frac{L_{57}}{L_{35}-L_{36}} y e^{L_{35} y}+\frac{L_{58}}{L_{36}-L_{35}} y e^{L_{36} y} \\
+ & \frac{L_{59}}{L_{47}} e^{\left(L_{2}+L_{3}\right) y}+\frac{L_{60}}{L_{48}} e^{\left(L_{1}+L_{3}\right) y}+\frac{L_{61}}{L_{49}} e^{\left(L_{2}+L_{4}\right) y} \\
+ & \frac{L_{62}}{L_{50}} e^{\left(L_{1}+L_{4}\right) y}+\frac{L_{63}}{L_{51}} e^{\left(L_{2}+L_{5}\right) y}+\frac{L_{64}}{L_{52}} e^{\left(L_{1}+L_{5}\right) y} \\
+ & \frac{L_{65}}{L_{53}} e^{\left(L_{2}+L_{6}\right) y}+\frac{L_{66}}{L_{54}} e^{\left(L_{1}+L_{6}\right) y} \\
+ & \frac{L_{67}}{L_{47}}\left(y-\frac{2\left(L_{2}+L_{3}\right)-R}{L_{47}}\right) e^{\left(L_{2}+L_{3}\right) y} \\
+ & \frac{L_{68}}{L_{48}}\left(y-\frac{2\left(L_{1}+L_{3}\right)-R}{L_{48}}\right) e^{\left(L_{1}+L_{3}\right) y} \\
+ & \frac{L_{69}}{L_{49}}\left(y-\frac{2\left(L_{2}+L_{4}\right)-R}{L_{49}}\right) e^{\left(L_{2}+L_{4}\right) y} \\
+ & \left.\left.\frac{L_{74}}{L_{54}}\left(y-\frac{2\left(L_{1}+L_{6}\right)-R}{L_{53}}\right) e^{\left(L_{1}+L_{6}\right) y}\right)\right) \cos \pi z \\
+ & \frac{L_{70}}{L_{50}}\left(y-\frac{2\left(L_{1}+L_{4}\right)-R}{L_{50}}\right) e^{\left(L_{1}+L_{4}\right) y} \\
+ & \frac{L_{71}}{L_{51}}\left(y-\frac{2\left(L_{2}+L_{5}\right) y}{L_{53}}\left(y-\frac{2\left(L_{1}\right)-R}{\left.L_{5}\right)-R}\right.\right. \\
& \\
\left.+L_{6}\right) &
\end{aligned}
$$

4.3. Shear Stress Components. The components of shear stress $F_{1}$ and $F_{2}$ in the $x$-direction and $z$-direction, respectively, on the lower plate are as follows:

$$
\begin{aligned}
& \tau_{z}=\frac{-\varepsilon}{\pi}\left(\frac{d v_{11}^{\prime}}{d y}\right)_{y=0} \sin \pi z, \\
& \tau_{x}=\left(\frac{d u_{0}}{d y}\right)_{y=0}+\varepsilon\left(\frac{d u_{11}}{d y}\right)_{y=0} \cos \pi z, \\
& F_{2}=\frac{-1}{\pi}\left(\frac{d v_{11}^{\prime}}{d y}\right)_{y=0}, \\
& F_{1}=\left(\frac{d u_{11}}{d y}\right)_{y=0} .
\end{aligned}
$$

So from (32) and (53), respectively, we have

$$
\begin{aligned}
F_{2} & =-\frac{1}{\pi}\left(L_{7} L_{3}^{2}+L_{8} L_{4}^{2}+L_{9} L_{5}^{2}+L_{10} L_{6}^{2}+\beta\left(L_{11} L_{3}^{2}\right.\right. \\
& +L_{12} L_{4}^{2}+L_{13} L_{5}^{2}+L_{14} L_{6}^{2} \\
& \left.\left.+2\left(L_{15} L_{3}+L_{16} L_{4}+L_{17} L_{5}+L_{18} L_{6}\right)\right)\right),
\end{aligned}
$$

$$
\begin{aligned}
& F_{1}=L_{25} L_{23}+L_{26} L_{24}+L_{27}\left(L_{2}+L_{3}\right)-L_{28}\left(L_{1}\right. \\
& \left.+L_{3}\right)+L_{29}\left(L_{2}+L_{4}\right)-L_{30}\left(L_{1}+L_{4}\right)+L_{31}\left(L_{2}\right. \\
& \left.+L_{5}\right)-L_{32}\left(L_{1}+L_{5}\right)+L_{33}\left(L_{2}+L_{6}\right)-L_{34}\left(L_{1}\right. \\
& \left.+L_{6}\right)+\beta\left(L_{43} L_{23}+L_{44} L_{24}+\frac{L_{45}}{L_{23}-L_{24}}\right. \\
& +\frac{L_{46}}{L_{24}-L_{23}}+\frac{L_{47}}{L_{35}}\left(L_{2}+L_{3}\right)+\frac{L_{48}}{L_{36}}\left(L_{1}+L_{3}\right) \\
& +\frac{L_{49}}{L_{37}}\left(L_{2}+L_{4}\right)+\frac{L_{50}}{L_{38}}\left(L_{1}+L_{4}\right)+\frac{L_{51}}{L_{39}}\left(L_{2}\right. \\
& \left.+L_{5}\right)+\frac{L_{52}}{L_{40}}\left(L_{1}+L_{5}\right)+\frac{L_{53}}{L_{41}}\left(L_{2}+L_{6}\right) \\
& +\frac{L_{54}}{L_{42}}\left(L_{1}+L_{6}\right)+\frac{L_{55}}{L_{35}}(1 \\
& \left.-\frac{\left(L_{2}+L_{3}\right)\left(2\left(L_{2}+L_{3}\right)-R\right)}{L_{35}}\right)+\frac{L_{56}}{L_{36}}(1 \\
& \left.-\frac{\left(L_{1}+L_{3}\right)\left(2\left(L_{1}+L_{3}\right)-R\right)}{L_{36}}\right)+\frac{L_{57}}{L_{37}}(1 \\
& \left.-\frac{\left(L_{2}+L_{4}\right)\left(2\left(L_{2}+L_{4}\right)-R\right)}{L_{37}}\right)+\frac{L_{58}}{L_{38}}(1 \\
& \left.-\frac{\left(L_{1}+L_{4}\right)\left(2\left(L_{1}+L_{4}\right)-R\right)}{L_{38}}\right)+\frac{L_{59}}{L_{39}}(1 \\
& \left.-\frac{\left(L_{2}+L_{5}\right)\left(2\left(L_{2}+L_{5}\right)-R\right)}{L_{39}}\right)+\frac{L_{60}}{L_{40}}(1 \\
& \left.-\frac{\left(L_{1}+L_{5}\right)\left(2\left(L_{1}+L_{5}\right)-R\right)}{L_{40}}\right)+\frac{L_{61}}{L_{41}}(1 \\
& \left.-\frac{\left(L_{2}+L_{6}\right)\left(2\left(L_{2}+L_{6}\right)-R\right)}{L_{41}}\right)+\frac{L_{62}}{L_{42}}(1 \\
& \left.\left.-\frac{\left(L_{1}+L_{6}\right)\left(2\left(L_{1}+L_{6}\right)-R\right)}{L_{42}}\right)\right) \text {, }
\end{aligned}
$$

where $L_{i}(i=19,20,21, \ldots, 74)$ are defined in the Appendix.

\section{Results and Discussion}

In this work, steady and fully developed laminar Couette flow of an incompressible Maxwell fluid through porous plates with periodic suction/injection is modelled and investigated analytically. The application of transverse sinusoidal injection at the lower plate remained stationary and its equivalent confiscation by suction through the uniformly moving upper plate leads to three-dimensional flow. The coupled highly nonlinear equations of motion are solved engaging perturbation method. The effects of various nondimensional 


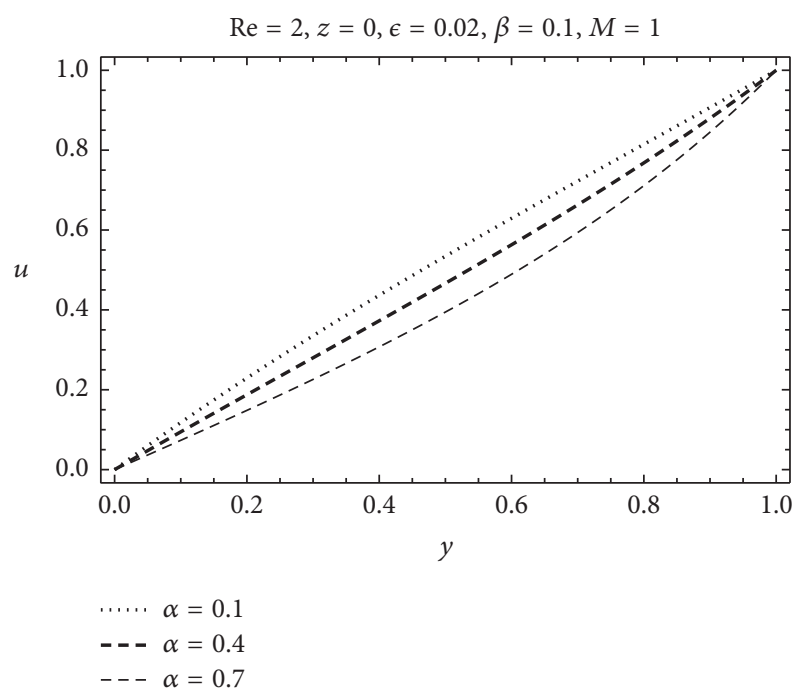

Figure 2: Variation of $u$ along $y$ for different values of $\alpha$.

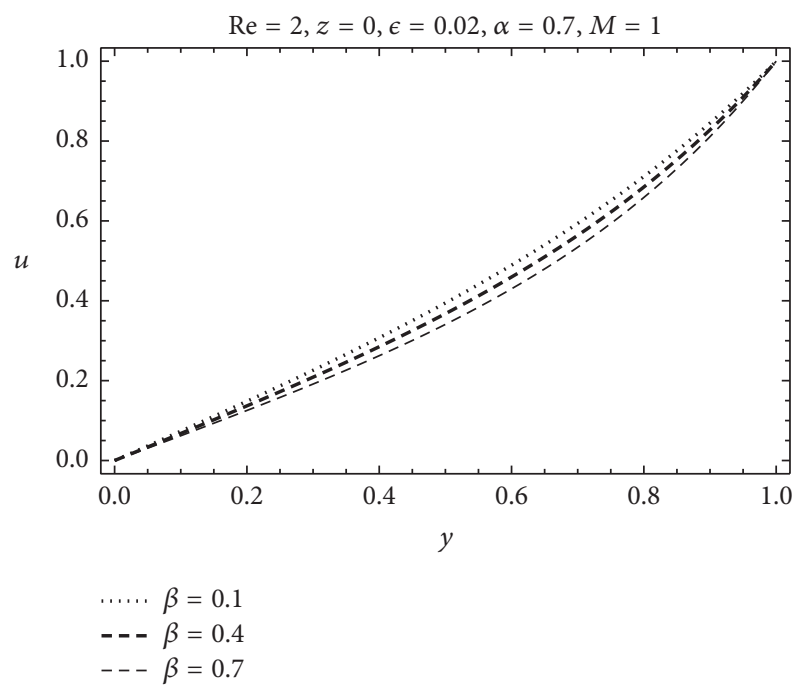

FIGURE 3: Variation of $u$ along $y$ for different values of $\beta$.

parameters on velocity field, skin friction components, and pressure are presented graphically in Figures 2-23.

The main flow velocity profiles are depicted in Figures $2-5$. The effects of injection/suction parameter $\alpha$, the Deborah number $\beta$, and Reynolds number Re are shown in Figures $2-4$, respectively. It is evident from Figure 2 that injection/suction parameter causes decrease in the main flow velocity component. In fact, fluid experiences greater viscosity with the porous boundaries and hence offers resistance to flow resulting in reduction in the velocity. It is noted that the velocity decreases exponentially with increasing the Deborah number or Reynolds number. For higher value of the Deborah number or Reynolds number, the decay is more. The minimum and maximum velocities occur on the plates, which are the velocities of the plates. It is noted that main flow velocity increases with the increase in Hartmann number $M$ (Figure 5).

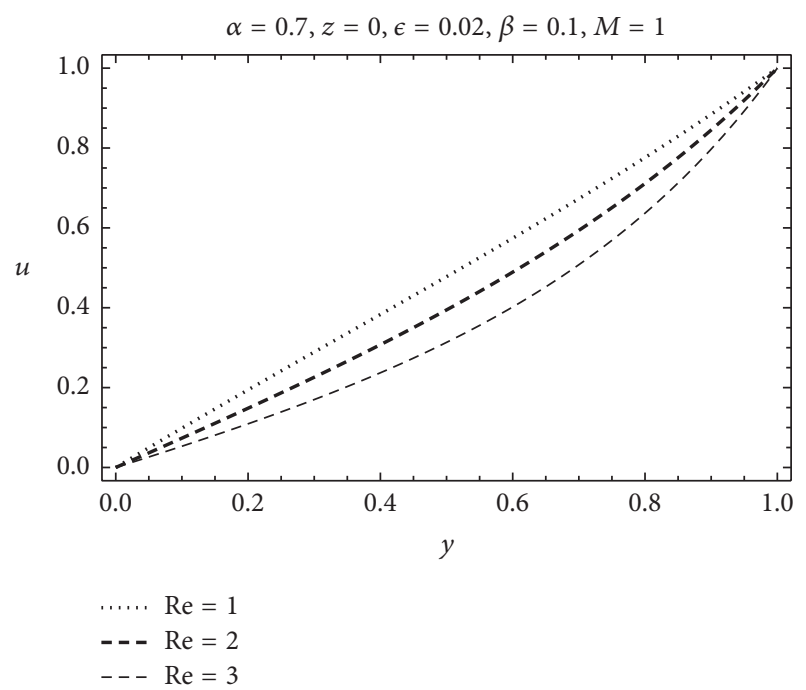

FIGURE 4: Variation of $u$ along $y$ for different values of Re.

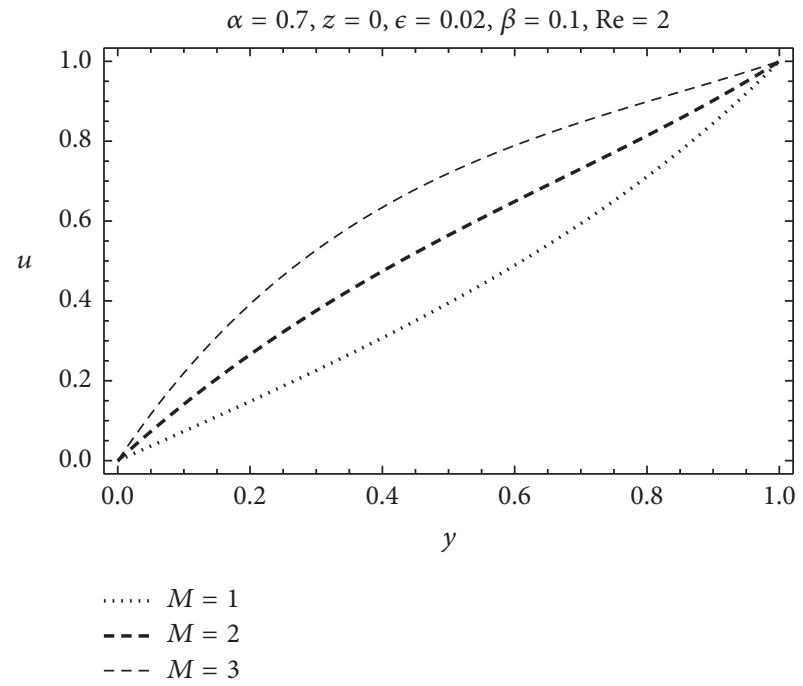

Figure 5: Variation of $u$ along $y$ for different values of $M$.

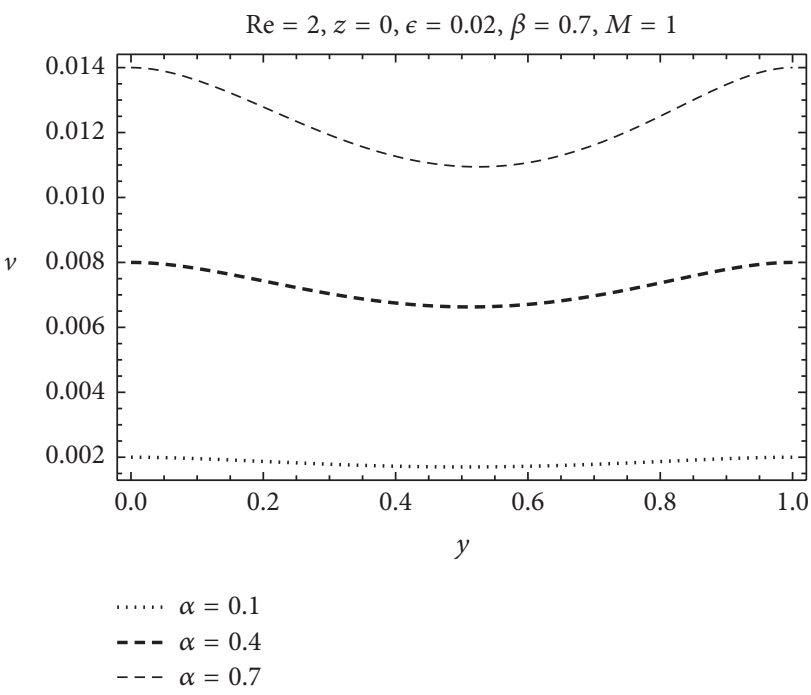

FiguRE 6: Variation of $v$ along $y$ for different values of $\alpha$. 


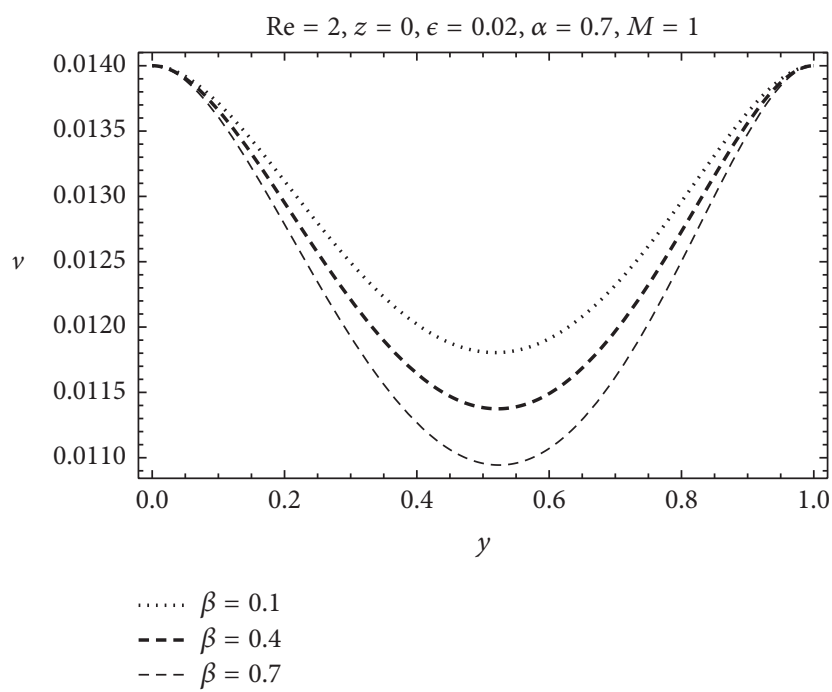

Figure 7: Variation of $v$ along $y$ for different values of $\beta$.

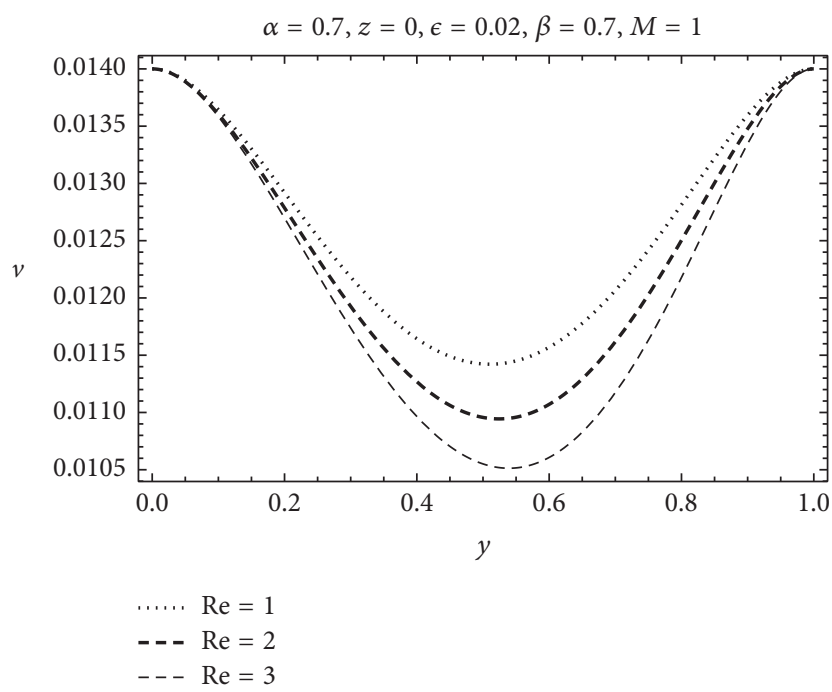

FIGURE 8: Variation of $v$ along $y$ for different values of Re.

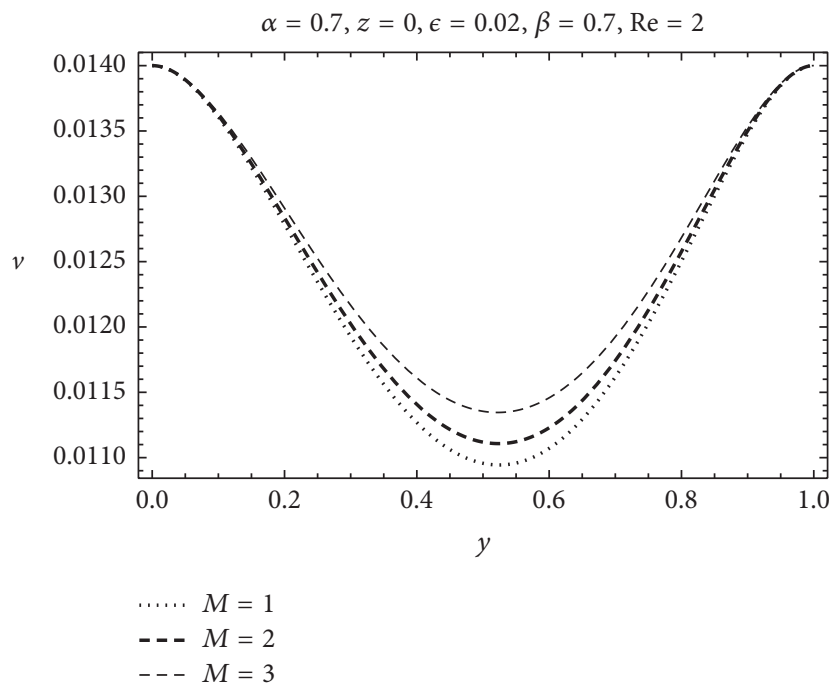

FIGURE 9: Variation of $v$ along $y$ for different values of $M$.

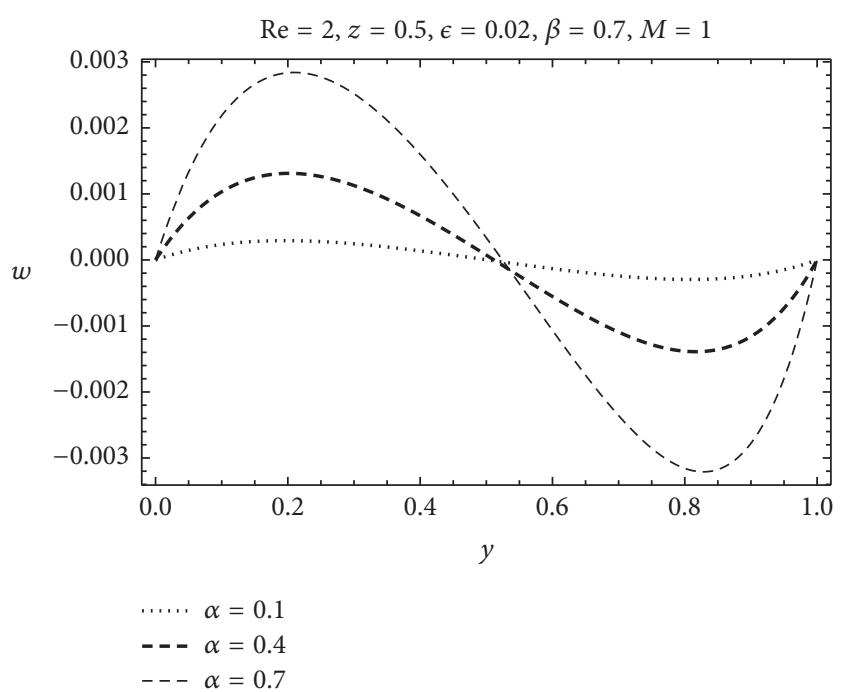

FigURE 10: Variation of $w$ along $y$ for different values of $\alpha$.

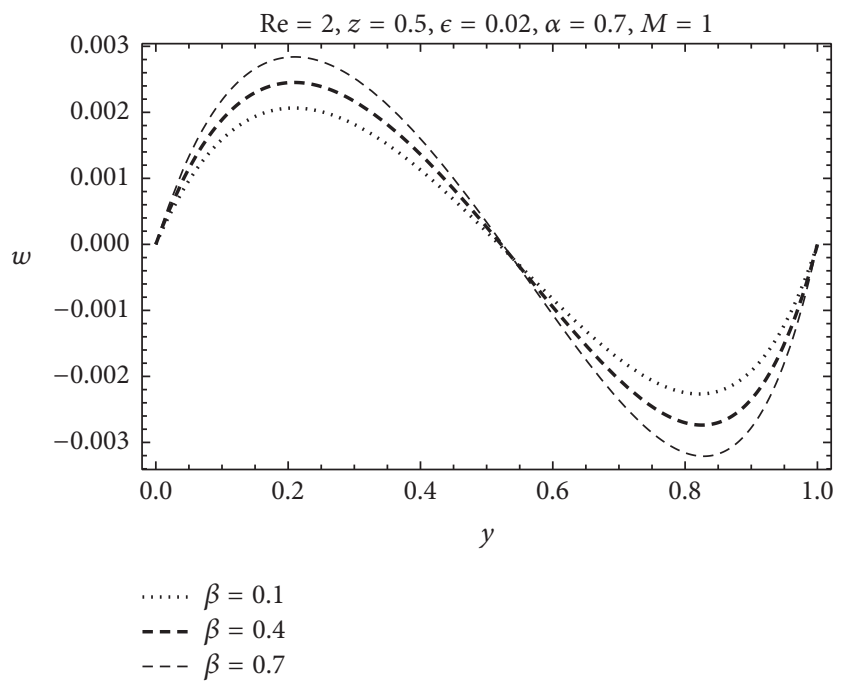

FIGURE 11: Variation of $w$ along $y$ for different values of $\beta$.

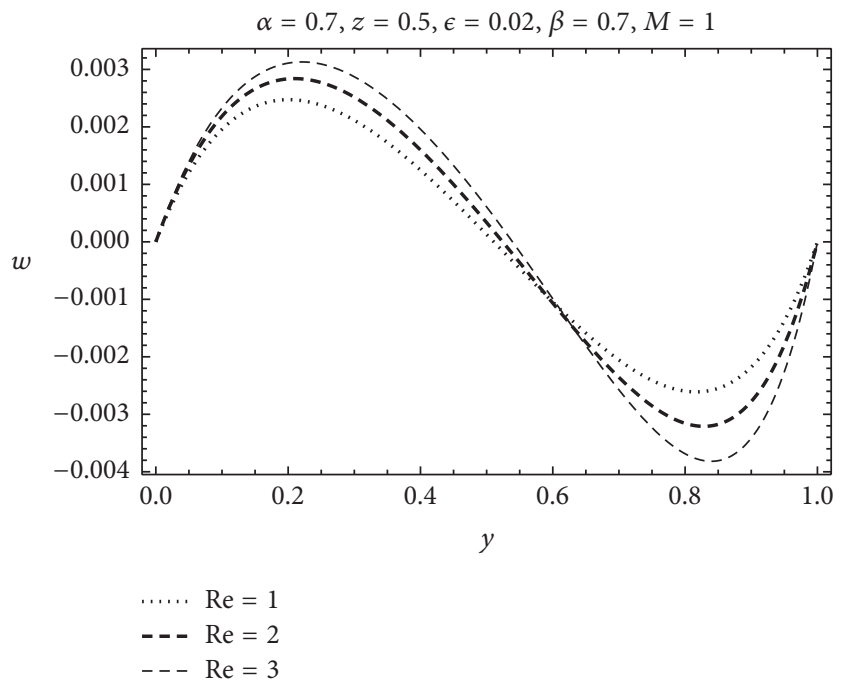

FIgURE 12: Variation of $w$ along $y$ for different values of Re. 

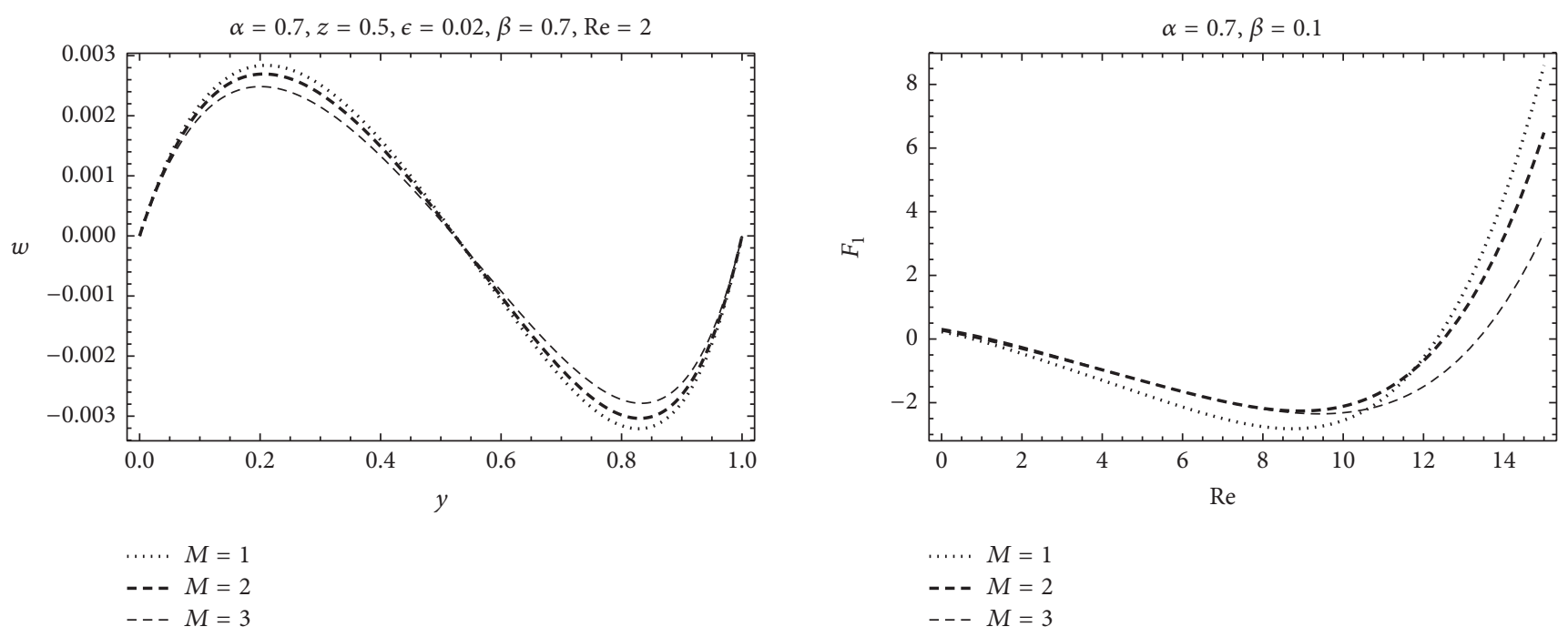

FIgURE 13: Variation of $w$ along $y$ for different values of $M$.

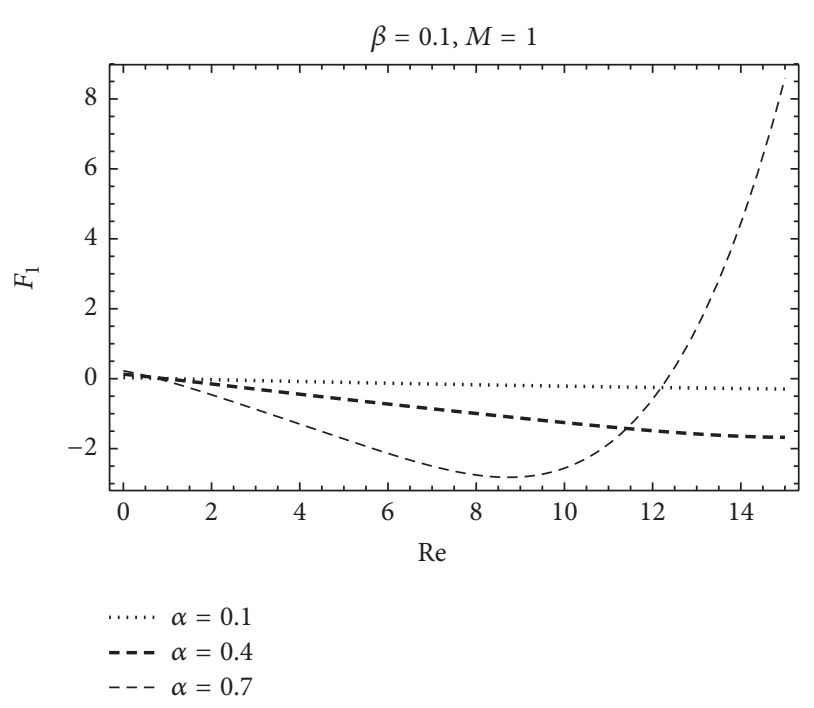

FIgURE 14: Variation of $F_{1}$ along Re for different values of $\alpha$.

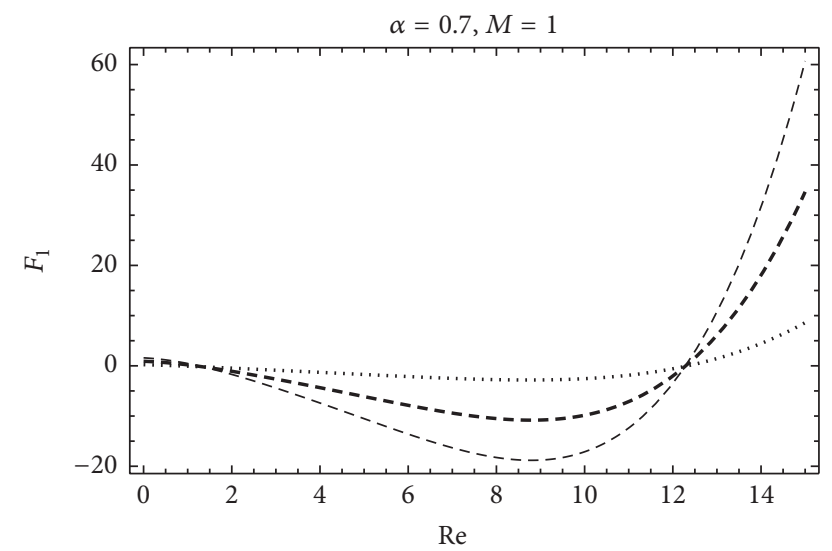

$$
\begin{aligned}
& \ldots \ldots=0.1 \\
& ---\beta=0.4 \\
& ---\beta=0.7
\end{aligned}
$$

FIgURE 15: Variation of $F_{1}$ along Re for different values of $\beta$.
Figure 16: Variation of $F_{1}$ along Re for different values of $M$.

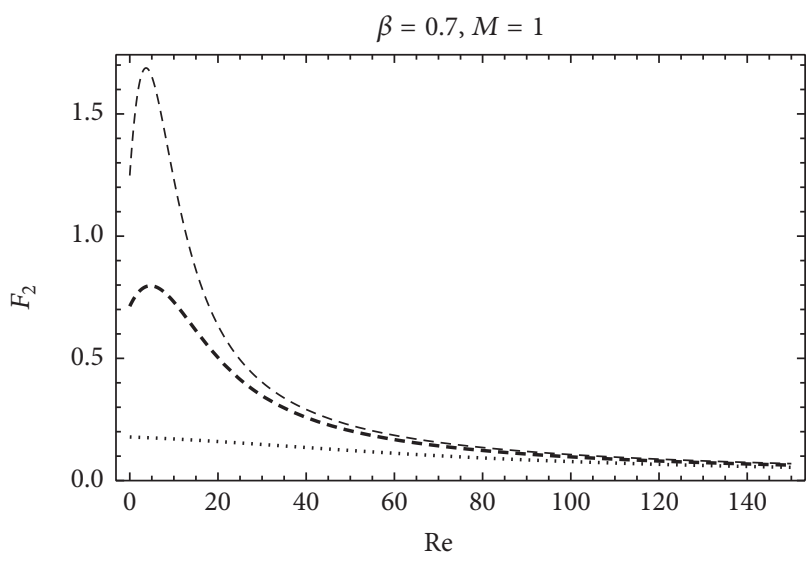

$$
\begin{aligned}
\ldots \ldots & \alpha=0.1 \\
---\alpha & =0.4 \\
---\alpha & =0.7
\end{aligned}
$$

FIgURE 17: Variation of $F_{2}$ along Re for different values of $\alpha$.

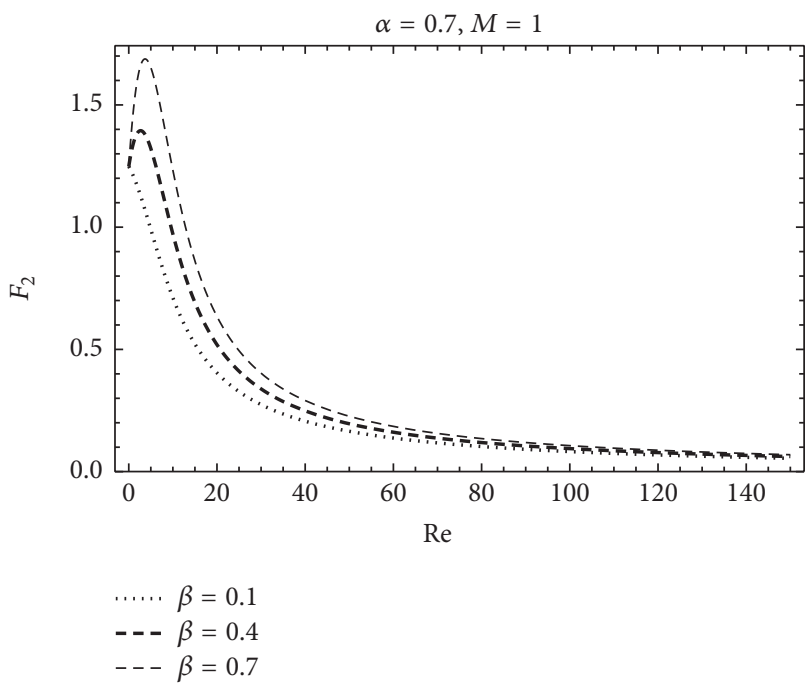

FIGURE 18: Variation of $F_{2}$ along Re for different values of $\beta$. 


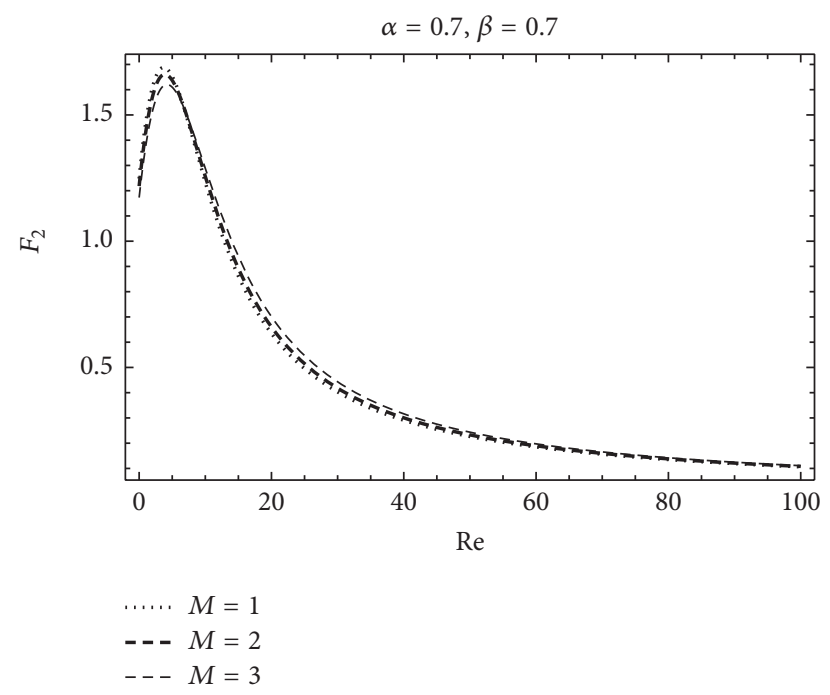

FIGURE 19: Variation of $F_{2}$ along Re for different values of $M$.

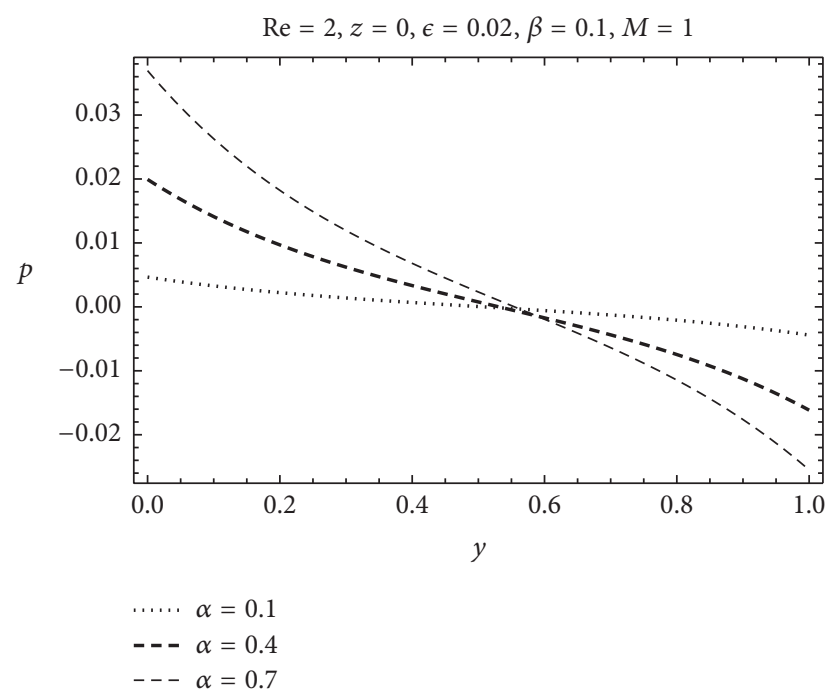

Figure 20: Variation of $p$ along $y$ for different values of $\alpha$.

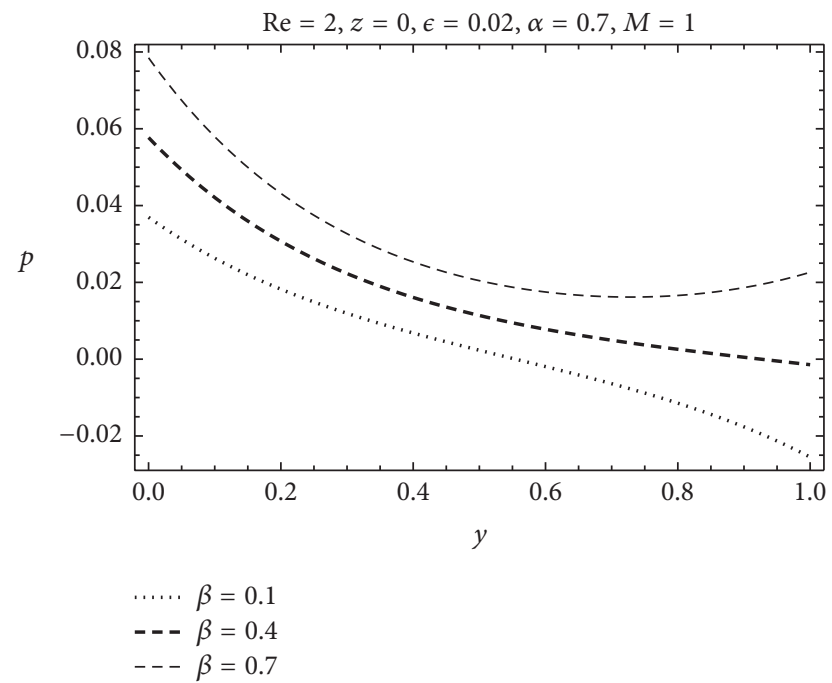

FIGURE 21: Variation of $p$ along $y$ for different values of $\beta$.

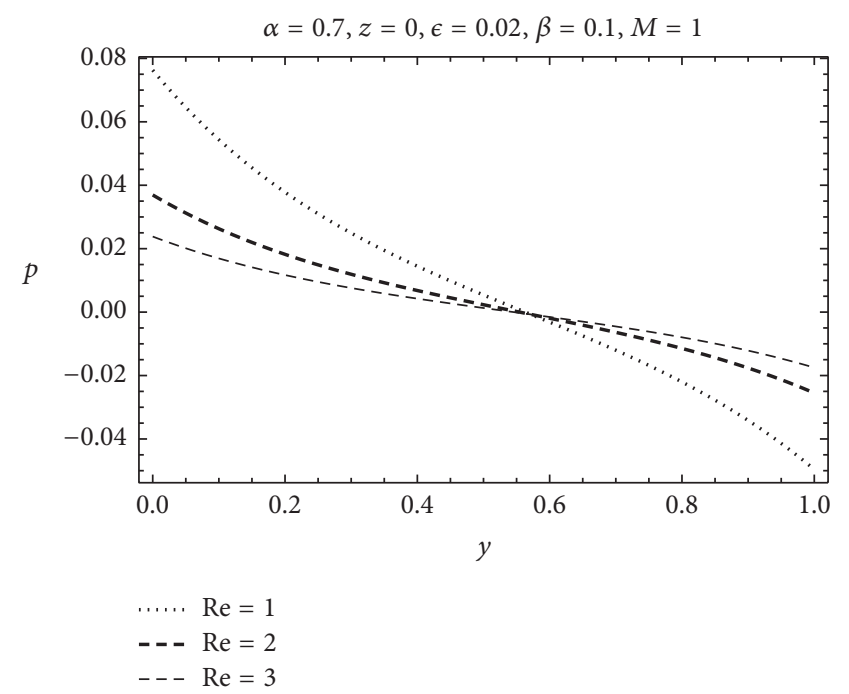

FIGURE 22: Variation of $p$ along $y$ for different values of Re.

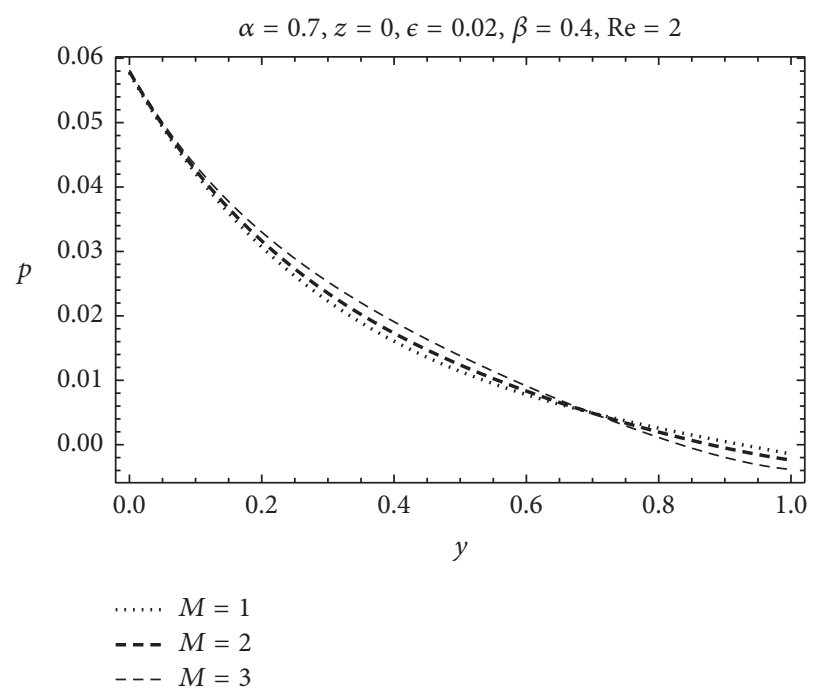

Figure 23: Variation of $p$ along $y$ for different values of $M$.

The influences of injection/suction parameter $\alpha$, the Deborah number $\beta$, Reynolds number Re, and Hartmann number $M$ on velocity component $v$ are shown in Figures $6-9$, respectively. It is observed from Figures 6 and 9 that the velocity increases with increasing the injection/suction parameter $\alpha$ and Hartmann number $M$. This means that injection/suction and Hartmann number provide a mechanism to enhance the velocity. Moreover, for $\alpha \leq 0.1$, the velocity profile behaves as a linear function; of course, for $\alpha \geq 0.4$, the velocity profile is parabolic. Figures 7 and 8 illustrate the effect of the Deborah number $\beta$ and Reynolds number $\operatorname{Re}$ on the velocity component. The velocity, as expected, decreases with an increase in the Deborah number or Reynolds number. Symmetric velocity profiles about the middle of the plates are obtained.

The transverse velocity component $w$ is studied for different values of injection/suction parameter $\alpha$, the Deborah 
number $\beta$, Reynolds number Re, and Hartmann number $M$ in Figures $10-13$. It is noted from Figure 10 that there is forward flow from $y=0$ to about $y=0.5$, and then, onwards, there is backward flow. In fact, the dragging effect of the faster layer exerted on the fluid particles near the lower plate (stationary plate) is sufficient to overcome the adverse pressure gradient, and hence there is forward flow. On the contrary, due to the periodic suction at the upper plate (moving plate), the dragging effect of the faster layer exerted on the fluid particles will be reduced, and hence this dragging effect is insufficient to overcome the adverse pressure gradient and there is backflow. It is also observed that the backflow is just the optical image of the forward flow. It is obvious from Figures 10-12 that the velocity component $w$ increases with an increase of $\alpha, \beta$, and Re in forward flow; however, a reverse effect is seen in the backward flow. On the contrary, the velocity component $w$ decreases with an increase in $M$ in forward flow, while it increases in backflow as shown in Figure 13.

The variations of skin friction components at the lower plate versus Reynolds number Re in the main flow direction and transverse directions are presented in Figures 14-19. Figures 14-16 depict the effect of injection/suction, the Deborah number, and Hartmann number on the skin friction component $F_{1}$. Depending upon the value of $\alpha$ and $\beta$, the value of $F_{1}$ decreases for small values of Reynolds number and then increases for large values of Reynolds numbers (Figures 14 and 15). Physically, it seems that for small values of Re viscous forces are dominant over the inertial forces, causing decrease in skin friction along the main flow direction, and skin friction is exerted by the plate on the fluid. On the contrary, for large values of Reynolds number, the inertial forces become dominant over the viscous forces, resulting in the change in direction of the skin friction; that is, the skin friction is exerted by the fluid on the plate which enhances by increasing the Reynolds number. Depending upon the value of Hartmann number $M$, the skin friction component $F_{1}$ decreases for small values of $M$ and then increases rapidly for large values of $M$ (Figure 16). It reflects that viscous forces are dominant over the electromagnetic forces for small Hartmann number resulting in reduction in skin friction exerted by the plate on the fluid along the $x$-direction. In contrast, the electromagnetic forces become dominant over the viscous forces for large $M$ leading to change of role of skin friction; that is, in this case, skin friction is exerted by the fluid on the plate which increases exponentially by increasing the Hartmann number.

Figures 17-19 are drawn for skin friction component along $z$-direction versus the Reynolds number for different values of injection/suction parameter $\alpha$, the Deborah number $\beta$, and Hartmann number $M$, respectively. It is observed that the skin friction component $F_{2}$ attains maximum value for particular value of $\alpha, \beta$, or $M$ and then reduces rapidly and approaches zero. The reduction in the skin friction exerted by the fluid on the plate for large values of Reynolds number happened due to the dominance of viscous forces over the inertial forces. Moreover, the skin friction exerted by the fluid on the plate increases by increasing suction parameter (for small value of Re). Then, of course, it approaches zero due to dominant role of viscous forces. Similar effect of the Deborah number $\beta$ on the skin friction component is observed. However, weak dependence of skin friction component along the $z$-direction is recorded. It is observed from Figure 19 that, with the increase of Hartmann number $M$, skin friction component $F_{2}$ decreases for small values of Reynolds number and increases for large values of Reynolds number and approaches zero for $\mathrm{Re} \geq 100$.

The effects of injection/suction parameter $\alpha$, the Deborah number $\beta$, Reynolds number Re, and Hartmann number $M$ on pressure are shown in Figures 20-23, respectively. It is noted from Figure 20 that, for an increase in injection/suction parameter $\alpha$, adverse pressure increases near the stationary plate; of course, favourable pressure increases near the moving plate. Physically, this means that injection at the lower plate promotes thickening of boundary layer, which in turn enhances the adverse pressure near the lower plate. On the contrary, suction through the upper moving plate causes thinning of boundary layer, resulting in enhancement in favourable pressure near the upper plate. Figure 21 indicates that adverse pressure increases near the stationary plate with increasing the Deborah number; however, it decreases near the moving plate and favourable pressure is noted near the moving plate for $\beta \leq 0.1$. Such behavior is expected because injection enhances adverse pressure (Figure 20) and the Deborah number also promotes the pressure and, therefore, ultimately large development in adverse pressure near the stationary plate. On the other hand, suction enhances favourable pressure (Figure 20), while the Deborah number enhances adverse pressure, resulting in combined effect in the form of favourable pressure for $\beta \leq 0.1$ near the moving plate. Figure 22 shows that adverse pressure decreases with an increase in Reynolds number in the vicinity of the lower plate and favourable pressure also decreases by increasing Reynolds number near the upper plate. It indicates that the dominance of inertial forces reduces the injection (at lower plate) and suction (through upper plate) effects, causing reduction in pressure in the neighborhood of the plates. Figure 23 indicates that pressure increases with an increase in Hartmann number and reverse effect can be observed near the moving plate.

\section{Concluding Remarks}

On the basis of above discussion, the following conclusions are made:

(1) The main flow velocity decreases with increasing either injection/suction parameter or Reynolds number. It decreases with an increase in the Deborah number.

(2) The velocity component $v$ and transverse velocity component $w$ increase with increasing injection/suction parameter; however, a reverse effect is observed with an increase in the Deborah number and Reynolds number.

(3) Reynolds number provides a mechanism to stabilize the skin friction components $F_{1}$ and $F_{2}$. 
(4) The present analysis gives a better result as variable injection/suction velocity is considered at both plates because in natural practice injection/suction cannot be uniform in all cases.

\section{Appendix}

Constants involved in this paper are

$$
\begin{aligned}
& L_{1}=\frac{R-\sqrt{R^{2}+4 M^{2}}}{2}, \\
& L_{2}=\frac{R+\sqrt{R^{2}+4 M^{2}}}{2}, \\
& L_{3}=\frac{L_{1}-\sqrt{\left(L_{1}\right)^{2}+4 \pi^{2}}}{2}, \\
& L_{4}=\frac{L_{1}+\sqrt{\left(L_{1}\right)^{2}+4 \pi^{2}}}{2}, \\
& L_{5}=\frac{L_{2}-\sqrt{\left(L_{2}\right)^{2}+4 \pi^{2}}}{2}, \\
& L_{6}=\frac{L_{2}+\sqrt{\left(L_{2}\right)^{2}+4 \pi^{2}}}{2}, \\
& L_{7}=\left(-e^{L_{4}} L_{4} L_{5} \alpha+e^{L_{5}} L_{4} L_{5} \alpha+e^{L_{4}+L_{6}} L_{4} L_{5} \alpha-e^{L_{5}+L_{6}} L_{4} L_{5} \alpha+e^{L_{4}} L_{4} L_{6} \alpha-e^{L_{4}+L_{5}} L_{4} L_{6} \alpha-e^{L_{6}} L_{4} L_{6} \alpha+e^{L_{5}+L_{6}} L_{4} L_{6} \alpha\right. \\
& \left.-e^{L_{5}} L_{5} L_{6} \alpha+e^{L_{4}+L_{5}} L_{5} L_{6} \alpha+e^{L_{6}} L_{5} L_{6} \alpha-e^{L_{4}+L_{6}} L_{5} L_{6} \alpha\right)\left(-e^{L_{3}+L_{4}} L_{3} L_{4}+e^{L_{4}+L_{5}} L_{3} L_{4}+e^{L_{3}+L_{6}} L_{3} L_{4}-e^{L_{4}+L_{6}} L_{3} L_{4}\right. \\
& +e^{L_{3}+L_{4}} L_{3} L_{5}-e^{L_{4}+L_{5}} L_{3} L_{5}-e^{L_{3}+L_{6}} L_{3} L_{5}+e^{L_{5}+L_{6}} L_{3} L_{5}-e^{L_{3}+L_{4}} L_{4} L_{5}+e^{L_{3}+L_{5}} L_{4} L_{5}+e^{L_{4}+L_{6}} L_{4} L_{5}-e^{L_{5}+L_{6}} L_{4} L_{5} \\
& -e^{L_{3}+L_{4}} L_{3} L_{6}+e^{L_{3}+L_{5}} L_{3} L_{6}+e^{L_{4}+L_{6}} L_{3} L_{6}-e^{L_{5}+L_{6}} L_{3} L_{6}+e^{L_{3}+L_{4}} L_{4} L_{6}-e^{L_{4}+L_{5}} L_{4} L_{6}-e^{L_{3}+L_{6}} L_{4} L_{6}+e^{L_{5}+L_{6}} L_{4} L_{6} \\
& \left.-e^{L_{3}+L_{5}} L_{5} L_{6}+e^{L_{4}+L_{5}} L_{5} L_{6}+e^{L_{3}+L_{6}} L_{5} L_{6}-e^{L_{4}+L_{6}} L_{5} L_{6}\right)^{-1} \text {, } \\
& L_{8}=\left(-e^{L_{3}} L_{3} L_{5} \alpha+e^{L_{5}} L_{3} L_{5} \alpha+e^{L_{3}+L_{6}} L_{3} L_{5} \alpha-e^{L_{5}+L_{6}} L_{3} L_{5} \alpha+e^{L_{3}} L_{3} L_{6} \alpha-e^{L_{3}+L_{5}} L_{3} L_{6} \alpha-e^{L_{6}} L_{3} L_{6} \alpha+e^{L_{5}+L_{6}} L_{3} L_{6} \alpha\right. \\
& \left.-e^{L_{5}} L_{5} L_{6} \alpha+e^{L_{3}+L_{5}} L_{5} L_{6} \alpha+e^{L_{6}} L_{5} L_{6} \alpha-e^{L_{3}+L_{6}} L_{5} L_{6} \alpha\right)\left(e^{L_{3}+L_{5}} L_{3} L_{4}-e^{L_{4}+L_{5}} L_{3} L_{4}-e^{L_{3}+L_{6}} L_{3} L_{4}+e^{L_{4}+L_{6}} L_{3} L_{4}\right. \\
& -e^{L_{3}+L_{4}} L_{3} L_{5}+e^{L_{4}+L_{5}} L_{3} L_{5}+e^{L_{3}+L_{6}} L_{3} L_{5}-e^{L_{5}+L_{6}} L_{3} L_{5}+e^{L_{3}+L_{4}} L_{4} L_{5}-e^{L_{3}+L_{5}} L_{4} L_{5}-e^{L_{4}+L_{6}} L_{4} L_{5}+e^{L_{5}+L_{6}} L_{4} L_{5} \\
& +e^{L_{3}+L_{4}} L_{3} L_{6}-e^{L_{3}+L_{5}} L_{3} L_{6}-e^{L_{4}+L_{6}} L_{3} L_{6}+e^{L_{5}+L_{6}} L_{3} L_{6}-e^{L_{3}+L_{4}} L_{4} L_{6}+e^{L_{4}+L_{5}} L_{4} L_{6}+e^{L_{3}+L_{6}} L_{4} L_{6}-e^{L_{5}+L_{6}} L_{4} L_{6} \\
& \left.+e^{L_{3}+L_{5}} L_{5} L_{6}-e^{L_{4}+L_{5}} L_{5} L_{6}-e^{L_{3}+L_{6}} L_{5} L_{6}+e^{L_{4}+L_{6}} L_{5} L_{6}\right)^{-1} \text {, } \\
& L_{9}=\left(-e^{L_{3}} L_{3} L_{4} \alpha+e^{L_{4}} L_{3} L_{4} \alpha+e^{L_{3}+L_{6}} L_{3} L_{4} \alpha-e^{L_{4}+L_{6}} L_{3} L_{4} \alpha+e^{L_{3}} L_{3} L_{6} \alpha-e^{L_{3}+L_{4}} L_{3} L_{6} \alpha-e^{L_{6}} L_{3} L_{6} \alpha+e^{L_{4}+L_{6}} L_{3} L_{6} \alpha\right. \\
& \left.-e^{L_{4}} L_{4} L_{6} \alpha+e^{L_{3}+L_{4}} L_{4} L_{6} \alpha+e^{L_{6}} L_{4} L_{6} \alpha-e^{L_{3}+L_{6}} L_{4} L_{6} \alpha\right)\left(-e^{L_{3}+L_{5}} L_{3} L_{4}+e^{L_{4}+L_{5}} L_{3} L_{4}+e^{L_{3}+L_{6}} L_{3} L_{4}-e^{L_{4}+L_{6}} L_{3} L_{4}\right. \\
& +e^{L_{3}+L_{4}} L_{3} L_{5}-e^{L_{4}+L_{5}} L_{3} L_{5}-e^{L_{3}+L_{6}} L_{3} L_{5}+e^{L_{5}+L_{6}} L_{3} L_{5}-e^{L_{3}+L_{4}} L_{4} L_{5}+e^{L_{3}+L_{5}} L_{4} L_{5}+e^{L_{4}+L_{6}} L_{4} L_{5}-e^{L_{5}+L_{6}} L_{4} L_{5} \\
& -e^{L_{3}+L_{4}} L_{3} L_{6}+e^{L_{3}+L_{5}} L_{3} L_{6}+e^{L_{4}+L_{6}} L_{3} L_{6}-e^{L_{5}+L_{6}} L_{3} L_{6}+e^{L_{3}+L_{4}} L_{4} L_{6}-e^{L_{4}+L_{5}} L_{4} L_{6}-e^{L_{3}+L_{6}} L_{4} L_{6}+e^{L_{5}+L_{6}} L_{4} L_{6} \\
& \left.-e^{L_{3}+L_{5}} L_{5} L_{6}+e^{L_{4}+L_{5}} L_{5} L_{6}+e^{L_{3}+L_{6}} L_{5} L_{6}-e^{L_{4}+L_{6}} L_{5} L_{6}\right)^{-1} \text {, } \\
& L_{10}=\left(-\left(\left(-e^{L_{3}}+e^{L_{5}}\right)\left(-L_{3}+L_{4}\right)-\left(-e^{L_{3}}+e^{L_{4}}\right)\left(-L_{3}+L_{5}\right)\right)\left(-e^{L_{3}} L_{3}\left(-L_{3}+L_{4}\right) \alpha+L_{3}\left(-e^{L_{3}} L_{3}+e^{L_{4}} L_{4}\right) \alpha\right)\right. \\
& \left.+\left(-e^{L_{3}} L_{3} L_{4}+e^{L_{4}} L_{3} L_{4}+e^{L_{3}} L_{3} L_{5}-e^{L_{5}} L_{3} L_{5}-e^{L_{4}} L_{4} L_{5}+e^{L_{5}} L_{4} L_{5}\right)\left(\left(-e^{L_{3}}+e^{L_{4}}\right) L_{3} \alpha+\left(-L_{3}+L_{4}\right)\left(\alpha-L_{3} \alpha\right)\right)\right) \\
& \cdot\left(( - e ^ { L _ { 3 } } L _ { 3 } L _ { 4 } + e ^ { L _ { 4 } } L _ { 3 } L _ { 4 } + e ^ { L _ { 3 } } L _ { 3 } L _ { 5 } - e ^ { L _ { 5 } } L _ { 3 } L _ { 5 } - e ^ { L _ { 4 } } L _ { 4 } L _ { 5 } + e ^ { L _ { 5 } } L _ { 4 } L _ { 5 } ) \left(\left(-e^{L_{3}}+e^{L_{6}}\right)\left(-L_{3}+L_{4}\right)-\left(-e^{L_{3}}+e^{L_{4}}\right)\left(-L_{3}\right.\right.\right.
\end{aligned}
$$




$$
\begin{aligned}
& \left.\left.+L_{6}\right)\right)-\left(\left(-e^{L_{3}}+e^{L_{5}}\right)\left(-L_{3}+L_{4}\right)-\left(-e^{L_{3}}+e^{L_{4}}\right)\left(-L_{3}+L_{5}\right)\right)\left(-\left(-e^{L_{3}} L_{3}+e^{L_{4}} L_{4}\right)\left(-L_{3}+L_{6}\right)+\left(-L_{3}+L_{4}\right)\right. \\
& \left.\left.\cdot\left(-e^{L_{3}} L_{3}+e^{L_{6}} L_{6}\right)\right)\right)^{-1} \text {, } \\
& L_{11}=-\frac{L_{15}+L_{16}+L_{17}+L_{18}}{L_{3}-L_{4}}-\left(\left(-\left(-e^{L_{3}}+e^{L_{4}}\right)\left(-L_{15}-L_{16}-L_{17}-L_{18}\right)+\left(-e^{L_{3}} L_{15}-e^{L_{4}} L_{16}-e^{L_{5}} L_{17}-e^{L_{6}} L_{18}\right)\right.\right. \\
& \left.\cdot\left(-L_{3}+L_{4}\right)\left(1-\frac{-L_{3}+L_{5}}{-L_{3}+L_{4}}\right)\right)\left(e^{L_{4}} L_{3}-e^{L_{5}} L_{3}-e^{L_{3}} L_{4}+e^{L_{5}} L_{4}+e^{L_{3}} L_{5}-e^{L_{4}} L_{5}\right)^{-1}+\left(\left(-e^{L_{5}} L_{4}+e^{L_{6}} L_{4}+e^{L_{4}} L_{5}\right.\right. \\
& \left.-e^{L_{6}} L_{5}-e^{L_{4}} L_{6}+e^{L_{5}} L_{6}\right) \\
& \cdot\left(-\left(-\left(-e^{L_{3}}+e^{L_{4}}\right)\left(-L_{15}-L_{16}-L_{17}-L_{18}\right)+\left(-e^{L_{3}} L_{15}-e^{L_{4}} L_{16}-e^{L_{5}} L_{17}-e^{L_{6}} L_{18}\right)\left(-L_{3}+L_{4}\right)\right)\right. \\
& \left.\cdot\left(-e^{L_{3}} L_{3}+e^{L_{4}} L_{4}\right)\left(-L_{3}+L_{5}\right)+\left(-L_{3}+L_{4}\right)\left(-e^{L_{3}} L_{3}+e^{L_{5}} L_{5}\right)\right)+\left(e^{L_{4}} L_{3}-e^{L_{5}} L_{3}-e^{L_{3}} L_{4}+e^{L_{5}} L_{4}+e^{L_{3}} L_{5}\right. \\
& \left.-e^{L_{4}} L_{5}\right)\left(-\left(-L_{15}-L_{16}-L_{17}-L_{18}\right)\left(-e^{L_{3}} L_{3}+e^{L_{4}} L_{4}\right)+\left(-L_{3}+L_{4}\right)\right. \\
& \left.\left.\left.\cdot\left(-e^{L_{3}} L_{15}\left(1+L_{3}\right)-e^{L_{4}} L_{16}\left(1+L_{4}\right)-e^{L_{5}} L_{17}\left(1+L_{5}\right)-e^{L_{6}} L_{18}\left(1+L_{6}\right)\right)\right)\right)\right)\left(\left(e^{L_{4}} L_{3}-e^{L_{5}} L_{3}-e^{L_{3}} L_{4}+e^{L_{5}} L_{4}\right.\right. \\
& \left.+e^{L_{3}} L_{5}-e^{L_{4}} L_{5}\right)\left(-\left(-\left(-e^{L_{3}} L_{3}+e^{L_{4}} L_{4}\right)\left(-L_{3}+L_{5}\right)+\left(-L_{3}+L_{4}\right)\left(-e^{L_{3}} L_{3}+e^{L_{5}} L_{5}\right)\right)\left(\left(-e^{L_{3}}+e^{L_{6}}\right)\left(-L_{3}+L_{4}\right)\right.\right. \\
& \left.-\left(-e^{L_{3}}+e^{L_{4}}\right)\left(-L_{3}+L_{6}\right)\right)+\left(e^{L_{4}} L_{3}-e^{L_{5}} L_{3}-e^{L_{3}} L_{4}+e^{L_{5}} L_{4}+e^{L_{3}} L_{5}-e^{L_{4}} L_{5}\right)\left(-\left(-e^{L_{3}} L_{3}+e^{L_{4}} L_{4}\right)\left(-L_{3}+L_{6}\right)\right. \\
& \left.\left.\left.+\left(-L_{3}+L_{4}\right)\left(-e^{L_{3}} L_{3}+e^{L_{6}} L_{6}\right)\right)\right)\right)^{-1} \\
& L_{12}=\frac{L_{15}+L_{16}+L_{17}+L_{18}}{L_{3}-L_{4}}-\left(\left(-\left(-e^{L_{3}}+e^{L_{4}}\right)\left(-L_{15}-L_{16}-L_{17}-L_{18}\right)+\left(-e^{L_{3}} L_{15}-e^{L_{4}} L_{16}-e^{L_{5}} L_{17}-e^{L_{6}} L_{18}\right)\right.\right. \\
& \left.\cdot\left(-L_{3}+L_{4}\right)\left(-L_{3}+L_{5}\right)\right)\left(\left(-L_{3}+L_{4}\right)\left(e^{L_{4}} L_{3}-e^{L_{5}} L_{3}-e^{L_{3}} L_{4}+e^{L_{5}} L_{4}+e^{L_{3}} L_{5}-e^{L_{4}} L_{5}\right)\right. \\
& +\left(\left(e^{L_{5}} L_{3}-e^{L_{6}} L_{3}-e^{L_{3}} L_{5}+e^{L_{6}} L_{5}+e^{L_{3}} L_{6}-e^{L_{5}} L_{6}\right)\right) \\
& \cdot\left(-\left(-\left(-e^{L_{3}}+e^{L_{4}}\right)\left(-L_{15}-L_{16}-L_{17}-L_{18}\right)+\left(-e^{L_{3}} L_{15}-e^{L_{4}} L_{16}-e^{L_{5}} L_{17}-e^{L_{6}} L_{18}\right)\left(-L_{3}+L_{4}\right)\right)\right. \\
& \left.\cdot\left(-e^{L_{3}} L_{3}+e^{L_{4}} L_{4}\right)\left(-L_{3}+L_{5}\right)+\left(-L_{3}+L_{4}\right)\left(-e^{L_{3}} L_{3}+e^{L_{5}} L_{5}\right)\right)+\left(e^{L_{4}} L_{3}-e^{L_{5}} L_{3}-e^{L_{3}} L_{4}+e^{L_{5}} L_{4}+e^{L_{3}} L_{5}\right. \\
& \left.-e^{L_{4}} L_{5}\right)\left(-\left(-L_{15}-L_{16}-L_{17}-L_{18}\right)\left(-e^{L_{3}} L_{3}+e^{L_{4}} L_{4}\right)+\left(-L_{3}+L_{4}\right)\right. \\
& \left.\left.\left.\cdot\left(-e^{L_{3}} L_{15}\left(1+L_{3}\right)-e^{L_{4}} L_{16}\left(1+L_{4}\right)-e^{L_{5}} L_{17}\left(1+L_{5}\right)-e^{L_{6}} L_{18}\left(1+L_{6}\right)\right)\right)\right)^{-1}\right)\left(\left(e^{L_{4}} L_{3}-e^{L_{5}} L_{3}-e^{L_{3}} L_{4}+e^{L_{5}} L_{4}\right.\right. \\
& \left.+e^{L_{3}} L_{5}-e^{L_{4}} L_{5}\right)\left(-\left(-\left(-e^{L_{3}} L_{3}+e^{L_{4}} L_{4}\right)\left(-L_{3}+L_{5}\right)+\left(-L_{3}+L_{4}\right)\left(-e^{L_{3}} L_{3}+e^{L_{5}} L_{5}\right)\right)\left(\left(-e^{L_{3}}+e^{L_{6}}\right)\left(-L_{3}+L_{4}\right)\right.\right. \\
& \left.-\left(-e^{L_{3}}+e^{L_{4}}\right)\left(-L_{3}+L_{6}\right)\right)+\left(e^{L_{4}} L_{3}-e^{L_{5}} L_{3}-e^{L_{3}} L_{4}+e^{L_{5}} L_{4}+e^{L_{3}} L_{5}-e^{L_{4}} L_{5}\right)\left(-\left(-e^{L_{3}} L_{3}+e^{L_{4}} L_{4}\right)\left(-L_{3}+L_{6}\right)\right. \\
& \left.\left.\left.+\left(-L_{3}+L_{4}\right)\left(-e^{L_{3}} L_{3}+e^{L_{6}} L_{6}\right)\right)\right)\right)^{-1} \\
& L_{13}=\left(-\left(-e^{L_{3}}+e^{L_{4}}\right)\left(-L_{15}-L_{16}-L_{17}-L_{18}\right)+\left(-e^{L_{3}} L_{15}-e^{L_{4}} L_{16}-e^{L_{5}} L_{17}-e^{L_{6}} L_{18}\right)\left(-L_{3}+L_{4}\right)\right)\left(e^{L_{4}} L_{3}-e^{L_{5}} L_{3}\right. \\
& \left.-e^{L_{3}} L_{4}+e^{L_{5}} L_{4}+e^{L_{3}} L_{5}-e^{L_{4}} L_{5}\right)^{-1}-\left(( ( - e ^ { L _ { 3 } } + e ^ { L _ { 6 } } ) ( - L _ { 3 } + L _ { 4 } ) - ( - e ^ { L _ { 3 } } + e ^ { L _ { 4 } } ) ( - L _ { 3 } + L _ { 6 } ) ) \left(-\left(-\left(-e^{L_{3}}+e^{L_{4}}\right)\right.\right.\right. \\
& \left.\cdot\left(-L_{15}-L_{16}-L_{17}-L_{18}\right)+\left(-e^{L_{3}} L_{15}-e^{L_{4}} L_{16}-e^{L_{5}} L_{17}-e^{L_{6}} L_{18}\right)\left(-L_{3}+L_{4}\right)\right)\left(-\left(-e^{L_{3}} L_{3}+e^{L_{4}} L_{4}\right)\left(-L_{3}+L_{5}\right)\right. \\
& \left.+\left(-L_{3}+L_{4}\right)\left(-e^{L_{3}} L_{3}+e^{L_{5}} L_{5}\right)\right)+\left(e^{L_{4}} L_{3}-e^{L_{5}} L_{3}-e^{L_{3}} L_{4}+e^{L_{5}} L_{4}+e^{L_{3}} L_{5}-e^{L_{4}} L_{5}\right)\left(-\left(L_{15}+L_{16}+L_{17}+L_{18}\right)\right. \\
& \left.\left.\left.\cdot\left(-e^{L_{3}} L_{3}+e^{L_{4}} L_{4}\right)+\left(-L_{3}+L_{4}\right)\left(e^{L_{3}} L_{15}\left(1+L_{3}\right)+e^{L_{4}} L_{16}\left(1+L_{4}\right)+e^{L_{5}} L_{17}\left(1+L_{5}\right)+e^{L_{6}} L_{18}\left(1+L_{6}\right)\right)\right)\right)\right) \\
& \text { - }\left(( e ^ { L _ { 4 } } L _ { 3 } - e ^ { L _ { 5 } } L _ { 3 } - e ^ { L _ { 3 } } L _ { 4 } + e ^ { L _ { 5 } } L _ { 4 } + e ^ { L _ { 3 } } L _ { 5 } - e ^ { L _ { 4 } } L _ { 5 } ) \left(-\left(-\left(-e^{L_{3}} L_{3}+e^{L_{4}} L_{4}\right)\left(-L_{3}+L_{5}\right)+\left(-L_{3}+L_{4}\right)\right.\right.\right.
\end{aligned}
$$




$$
\begin{aligned}
& \left.\cdot\left(-e^{L_{3}} L_{3}+e^{L_{5}} L_{5}\right)\right)\left(\left(-e^{L_{3}}+e^{L_{6}}\right)\left(-L_{3}+L_{4}\right)-\left(-e^{L_{3}}+e^{L_{4}}\right)\left(-L_{3}+L_{6}\right)\right)+\left(e^{L_{4}} L_{3}-e^{L_{5}} L_{3}-e^{L_{3}} L_{4}+e^{L_{5}} L_{4}\right. \\
& \left.\left.\left.+e^{L_{3}} L_{5}-e^{L_{4}} L_{5}\right)\left(-\left(-e^{L_{3}} L_{3}+e^{L_{4}} L_{4}\right)\left(-L_{3}+L_{6}\right)+\left(-L_{3}+L_{4}\right)\left(-e^{L_{3}} L_{3}+e^{L_{6}} L_{6}\right)\right)\right)\right)^{-1}, \\
& L_{14}=\left(-\left(-\left(-e^{L_{3}}+e^{L_{4}}\right)\left(-L_{15}-L_{16}-L_{17}-L_{18}\right)+\left(-e^{L_{3}} L_{15}-e^{L_{4}} L_{16}-e^{L_{5}} L_{17}-e^{L_{6}} L_{18}\right)\left(-L_{3}+L_{4}\right)\right)\left(-\left(-e^{L_{3}} L_{3}\right.\right.\right. \\
& \left.\left.+e^{L_{4}} L_{4}\right)\left(-L_{3}+L_{5}\right)+\left(-L_{3}+L_{4}\right)\left(-e^{L_{3}} L_{3}+e^{L_{5}} L_{5}\right)\right)+\left(e^{L_{4}} L_{3}-e^{L_{5}} L_{3}-e^{L_{3}} L_{4}+e^{L_{5}} L_{4}+e^{L_{3}} L_{5}-e^{L_{4}} L_{5}\right)\left(-\left(-L_{15}\right.\right. \\
& \left.-L_{16}-L_{17}-L_{18}\right)\left(-e^{L_{3}} L_{3}+e^{L_{4}} L_{4}\right)+\left(-L_{3}+L_{4}\right)\left(-e^{L_{3}} L_{15}\left(1+L_{3}\right)-e^{L_{4}} L_{16}\left(1+L_{4}\right)-e^{L_{5}} L_{17}\left(1+L_{5}\right)\right. \\
& \left.\left.\left.-e^{L_{6}} L_{18}\left(1+L_{6}\right)\right)\right)\right)\left(-\left(-\left(-e^{L_{3}} L_{3}+e^{L_{4}} L_{4}\right)\left(-L_{3}+L_{5}\right)+\left(-L_{3}+L_{4}\right)\left(-e^{L_{3}} L_{3}+e^{L_{5}} L_{5}\right)\right)\left(\left(-e^{L_{3}}+e^{L_{6}}\right)\left(-L_{3}+L_{4}\right)\right.\right. \\
& \left.-\left(-e^{L_{3}}+e^{L_{4}}\right)\left(-L_{3}+L_{6}\right)\right)+\left(e^{L_{4}} L_{3}-e^{L_{5}} L_{3}-e^{L_{3}} L_{4}+e^{L_{5}} L_{4}+e^{L_{3}} L_{5}-e^{L_{4}} L_{5}\right)\left(-\left(-e^{L_{3}} L_{3}+e^{L_{4}} L_{4}\right)\left(-L_{3}+L_{6}\right)\right. \\
& \left.\left.+\left(-L_{3}+L_{4}\right)\left(-e^{L_{3}} L_{3}+e^{L_{6}} L_{6}\right)\right)\right)^{-1} \text {, } \\
& L_{15}=\frac{\alpha R L_{7} L_{3}^{2}\left(L_{3}^{2}-\pi^{2}\right)}{\left(L_{3}-L_{4}\right)\left(L_{3}-L_{5}\right)\left(L_{3}-L_{6}\right)}, \\
& L_{16}=\frac{\alpha R L_{8} L_{4}^{2}\left(L_{4}^{2}-\pi^{2}\right)}{\left(L_{4}-L_{3}\right)\left(L_{4}-L_{5}\right)\left(L_{4}-L_{6}\right)} \\
& L_{17}=\frac{\alpha R L_{9} L_{5}^{2}\left(L_{5}^{2}-\pi^{2}\right)}{\left(L_{5}-L_{3}\right)\left(L_{5}-L_{4}\right)\left(L_{5}-L_{6}\right)} \text {, } \\
& L_{18}=\frac{\alpha R L_{10} L_{6}^{2}\left(L_{6}^{2}-\pi^{2}\right)}{\left(L_{6}-L_{3}\right)\left(L_{6}-L_{4}\right)\left(L_{6}-L_{5}\right)} \text {, } \\
& L_{19}=\frac{L_{7} L_{3}}{\pi^{2} \operatorname{Re}}\left(L_{3}^{2}-R L_{3}-\left(\pi^{2}+M^{2}\right)\right), \\
& L_{20}=\frac{L_{8} L_{4}}{\pi^{2} \operatorname{Re}}\left(L_{4}^{2}-R L_{4}-\left(\pi^{2}+M^{2}\right)\right), \\
& L_{21}=\frac{L_{9} L_{5}}{\pi^{2} \operatorname{Re}}\left(L_{5}^{2}-R L_{5}-\left(\pi^{2}+M^{2}\right)\right) \text {, } \\
& L_{22}=\frac{L_{10} L_{6}}{\pi^{2} \operatorname{Re}}\left(L_{5}^{2}-R L_{5}-\left(\pi^{2}+M^{2}\right)\right) \text {, } \\
& L_{23}=\frac{1}{\pi^{2} \operatorname{Re}}\left(\left(L_{3}^{2}-R L_{3}-\left(\pi^{2}+M^{2}\right)\right) L_{3} L_{11}+\left(3 L_{3}^{2}-2 R L_{3}-\left(\pi^{2}+M^{2}\right)\right) L_{15}\right)-\alpha\left(L_{19}+\frac{\alpha}{\pi^{2}} L_{7} L_{3}^{2}\right) L_{3}, \\
& L_{24}=\frac{1}{\pi^{2} \operatorname{Re}}\left(\left(L_{4}^{2}-R L_{4}-\left(\pi^{2}+M^{2}\right)\right) L_{4} L_{12}+\left(3 L_{4}^{2}-2 R L_{4}-\left(\pi^{2}+M^{2}\right)\right) L_{16}\right)-\alpha\left(L_{20}+\frac{\alpha}{\pi^{2}} L_{8} L_{4}^{2}\right) L_{4}, \\
& L_{25}=\frac{1}{\pi^{2} \operatorname{Re}}\left(\left(L_{5}^{2}-R L_{5}-\left(\pi^{2}+M^{2}\right)\right) L_{5} L_{13}+\left(3 L_{5}^{2}-2 R L_{5}-\left(\pi^{2}+M^{2}\right)\right) L_{17}\right)-\alpha\left(L_{21}+\frac{\alpha}{\pi^{2}} L_{9} L_{5}^{2}\right) L_{5}, \\
& L_{26}=\frac{1}{\pi^{2} \operatorname{Re}}\left(\left(L_{6}^{2}-R L_{6}-\left(\pi^{2}+M^{2}\right)\right) L_{6} L_{14}+\left(3 L_{6}^{2}-2 R L_{6}-\left(\pi^{2}+M^{2}\right)\right) L_{18}\right)-\alpha\left(L_{22}+\frac{\alpha}{\pi^{2}} L_{10} L_{6}^{2}\right) L_{6} \text {, } \\
& L_{27}=\frac{L_{15} L_{3}}{\pi^{2} \operatorname{Re}}\left(L_{3}^{2}-R L_{3}-\left(\pi^{2}+M^{2}\right)\right) \text {, } \\
& L_{28}=\frac{L_{16} L_{4}}{\pi^{2} \operatorname{Re}}\left(L_{4}^{2}-R L_{4}-\left(\pi^{2}+M^{2}\right)\right) \text {, } \\
& L_{29}=\frac{L_{17} L_{5}}{\pi^{2} \operatorname{Re}}\left(L_{5}^{2}-R L_{5}-\left(\pi^{2}+M^{2}\right)\right), \\
& L_{30}=\frac{L_{18} L_{6}}{\pi^{2} \operatorname{Re}}\left(L_{5}^{2}-R L_{5}-\left(\pi^{2}+M^{2}\right)\right),
\end{aligned}
$$




$$
\begin{aligned}
& L_{31}=\frac{\left(L_{21}+L_{22}\right) e^{L_{1}+L_{2}}}{e^{L_{2}}-e^{L_{1}}}, \\
& L_{32}=\frac{\left(L_{21}+L_{22}\right) e^{L_{1}+L_{2}}}{e^{L_{1}}-e^{L_{2}}}, \\
& L_{33}=\frac{\alpha R L_{2}^{2}}{\left(e^{L_{2}}-e^{L_{1}}\right)\left(L_{2}-L_{1}\right)}, \\
& L_{34}=\frac{\alpha R L_{1}^{2}}{\left(e^{L_{2}}-e^{L_{1}}\right)\left(L_{2}-L_{1}\right)}, \\
& L_{35}=\frac{R-\sqrt{R^{2}+4\left(\pi^{2}+M^{2}\right)}}{2}, \\
& L_{36}=\frac{R+\sqrt{R^{2}+4\left(\pi^{2}+M^{2}\right)}}{2}, \\
& L_{37}=\frac{1}{e^{L_{35}}-e^{L_{36}}}\left(L_{39}\left(e^{L_{36}}-e^{L_{2}+L_{3}}\right)-L_{40}\left(e^{L_{36}}-e^{L_{1}+L_{3}}\right)+L_{41}\left(e^{L_{36}}-e^{L_{2}+L_{4}}\right)-L_{42}\left(e^{L_{36}}-e^{L_{2}+L_{4}}\right)+L_{43}\left(e^{L_{36}}\right.\right. \\
& \left.\left.-e^{L_{2}+L_{5}}\right)-L_{44}\left(e^{L_{36}}-e^{L_{1}+L_{5}}\right)+L_{45}\left(e^{L_{36}}-e^{L_{2}+L_{6}}\right)-L_{46}\left(e^{L_{36}}-e^{L_{1}+L_{6}}\right)\right), \\
& L_{38}=\frac{1}{e^{L_{36}}-e^{L_{35}}}\left(L_{39}\left(e^{L_{35}}-e^{L_{2}+L_{3}}\right)-L_{40}\left(e^{L_{35}}-e^{L_{1}+L_{3}}\right)+L_{41}\left(e^{L_{35}}-e^{L_{2}+L_{4}}\right)-L_{42}\left(e^{L_{35}}-e^{L_{2}+L_{4}}\right)+L_{43}\left(e^{L_{35}}\right.\right. \\
& \left.\left.-e^{L_{2}+L_{5}}\right)-L_{44}\left(e^{L_{35}}-e^{L_{1}+L_{5}}\right)+L_{45}\left(e^{L_{35}}-e^{L_{2}+L_{6}}\right)-L_{46}\left(e^{L_{35}}-e^{L_{1}+L_{6}}\right)\right), \\
& L_{39}=\frac{\operatorname{Re} L_{7} L_{2} e^{L_{1}}}{\left(e^{L_{2}}-e^{L_{1}}\right) L_{47}}, \\
& L_{40}=\frac{\operatorname{Re} L_{7} L_{1} e^{L_{2}}}{\left(e^{L_{2}}-e^{L_{1}}\right) L_{48}} \\
& L_{41}=\frac{\operatorname{Re} L_{8} L_{2} e^{L_{1}}}{\left(e^{L_{2}}-e^{L_{1}}\right) L_{49}} \\
& L_{42}=\frac{\operatorname{Re} L_{8} L_{1} e^{L_{2}}}{\left(e^{L_{2}}-e^{L_{1}}\right) L_{50}} \\
& L_{43}=\frac{\operatorname{Re} L_{9} L_{2} e^{L_{1}}}{\left(e^{L_{2}}-e^{L_{1}}\right) L_{51}}, \\
& L_{44}=\frac{\operatorname{Re} L_{9} L_{1} e^{L_{2}}}{\left(e^{L_{2}}-e^{L_{1}}\right) L_{52}}, \\
& L_{45}=\frac{\operatorname{Re} L_{10} L_{2} e^{L_{1}}}{\left(e^{L_{2}}-e^{L_{1}}\right) L_{53}}, \\
& L_{46}=\frac{\operatorname{Re} L_{10} L_{1} e^{L_{2}}}{\left(e^{L_{2}}-e^{L_{1}}\right) L_{54}}, \\
& L_{47}=\left(L_{2}+L_{3}-L_{35}\right)\left(L_{2}+L_{3}-L_{36}\right) \text {, } \\
& L_{48}=\left(L_{1}+L_{3}-L_{35}\right)\left(L_{1}+L_{3}-L_{36}\right) \text {, } \\
& L_{49}=\left(L_{2}+L_{4}-L_{35}\right)\left(L_{2}+L_{4}-L_{36}\right) \text {, } \\
& L_{50}=\left(L_{1}+L_{4}-L_{35}\right)\left(L_{1}+L_{4}-L_{36}\right) \text {, }
\end{aligned}
$$




$$
\begin{aligned}
& L_{51}=\left(L_{2}+L_{5}-L_{35}\right)\left(L_{2}+L_{5}-L_{36}\right) \text {, } \\
& L_{52}=\left(L_{1}+L_{5}-L_{35}\right)\left(L_{1}+L_{5}-L_{36}\right) \text {, } \\
& L_{53}=\left(L_{2}+L_{6}-L_{35}\right)\left(L_{1}+L_{6}-L_{36}\right) \text {, } \\
& L_{54}=\left(L_{1}+L_{6}-L_{35}\right)\left(L_{1}+L_{6}-L_{36}\right) \text {, } \\
& L_{55}=\frac{1}{e^{L_{35}}-e^{L_{36}}}\left(\frac{L_{57}}{L_{36}-L_{35}} e^{L_{35}}+\frac{L_{58}}{L_{35}-L_{36}} e^{L_{36}}+\frac{L_{59}}{L_{47}}\left(e^{L_{36}}-e^{L_{2}+L_{3}}\right)+\frac{L_{60}}{L_{48}}\left(e^{L_{36}}-e^{L_{1}+L_{3}}\right)+\frac{L_{61}}{L_{49}}\left(e^{L_{36}}-e^{L_{2}+L_{4}}\right)\right. \\
& +\frac{L_{62}}{L_{50}}\left(e^{L_{36}}-e^{L_{1}+L_{4}}\right)+\frac{L_{63}}{L_{51}}\left(e^{L_{36}}-e^{L_{2}+L_{5}}\right)+\frac{L_{64}}{L_{52}}\left(e^{L_{36}}-e^{L_{1}+L_{5}}\right)+\frac{L_{65}}{L_{53}}\left(e^{L_{36}}-e^{L_{2}+L_{6}}\right)+\frac{L_{66}}{L_{54}}\left(e^{L_{36}}-e^{L_{1}+L_{6}}\right) \\
& -\frac{L_{67}}{L_{47}}\left(\left(1-\frac{2\left(L_{2}+L_{3}\right)-R}{L_{47}}\right) e^{L_{2}+L_{3}}+\frac{2\left(L_{2}+L_{3}\right)-R}{L_{47}} e^{L_{36}}\right)-\frac{L_{68}}{L_{48}}\left(\left(1-\frac{2\left(L_{1}+L_{3}\right)-R}{L_{48}}\right) e^{L_{1}+L_{3}}\right. \\
& \left.+\frac{2\left(L_{1}+L_{3}\right)-R}{L_{48}} e^{L_{36}}\right)-\frac{L_{69}}{L_{49}}\left(\left(1-\frac{2\left(L_{2}+L_{4}\right)-R}{L_{49}}\right) e^{L_{2}+L_{4}}+\frac{2\left(L_{2}+L_{4}\right)-R}{L_{49}} e^{L_{36}}\right)-\frac{L_{70}}{L_{50}}((1 \\
& \left.\left.-\frac{2\left(L_{1}+L_{4}\right)-R}{L_{50}}\right) e^{L_{1}+L_{4}}+\frac{2\left(L_{1}+L_{4}\right)-R}{L_{50}} e^{L_{36}}\right)-\frac{L_{71}}{L_{51}}\left(\left(1-\frac{2\left(L_{2}+L_{5}\right)-R}{L_{51}}\right) e^{L_{2}+L_{5}}+\frac{2\left(L_{2}+L_{5}\right)-R}{L_{51}} e^{L_{36}}\right) \\
& -\frac{L_{72}}{L_{52}}\left(\left(1-\frac{2\left(L_{1}+L_{5}\right)-R}{L_{52}}\right) e^{L_{1}+L_{5}}+\frac{2\left(L_{1}+L_{5}\right)-R}{L_{52}} e^{L_{36}}\right)-\frac{L_{73}}{L_{53}}\left(\left(1-\frac{2\left(L_{2}+L_{6}\right)-R}{L_{53}}\right) e^{L_{2}+L_{6}}\right. \\
& \left.\left.+\frac{2\left(L_{2}+L_{6}\right)-R}{L_{53}} e^{L_{36}}\right)-\frac{L_{74}}{L_{54}}\left(\left(1-\frac{2\left(L_{1}+L_{6}\right)-R}{L_{54}}\right) e^{L_{1}+L_{6}}+\frac{2\left(L_{1}+L_{6}\right)-R}{L_{54}} e^{L_{36}}\right)\right), \\
& L_{56}=\frac{1}{e^{L_{36}}-e^{L_{35}}}\left(\frac{L_{57}}{L_{36}-L_{35}} e^{L_{35}}+\frac{L_{58}}{L_{35}-L_{36}} e^{L_{36}}+\frac{L_{59}}{L_{47}}\left(e^{L_{35}}-e^{L_{2}+L_{3}}\right)+\frac{L_{60}}{L_{48}}\left(e^{L_{35}}-e^{L_{1}+L_{3}}\right)+\frac{L_{61}}{L_{49}}\left(e^{L_{35}}-e^{L_{2}+L_{4}}\right)\right. \\
& +\frac{L_{62}}{L_{50}}\left(e^{L_{35}}-e^{L_{1}+L_{4}}\right)+\frac{L_{63}}{L_{51}}\left(e^{L_{35}}-e^{L_{2}+L_{5}}\right)+\frac{L_{64}}{L_{52}}\left(e^{L_{35}}-e^{L_{1}+L_{5}}\right)+\frac{L_{65}}{L_{53}}\left(e^{L_{35}}-e^{L_{2}+L_{6}}\right)+\frac{L_{66}}{L_{54}}\left(e^{L_{35}}-e^{L_{1}+L_{6}}\right) \\
& -\frac{L_{67}}{L_{47}}\left(\left(1-\frac{2\left(L_{2}+L_{3}\right)-R}{L_{47}}\right) e^{L_{2}+L_{3}}+\frac{2\left(L_{2}+L_{3}\right)-R}{L_{47}} e^{L_{35}}\right)-\frac{L_{68}}{L_{48}}\left(\left(1-\frac{2\left(L_{1}+L_{3}\right)-R}{L_{48}}\right) e^{L_{1}+L_{3}}\right. \\
& \left.+\frac{2\left(L_{1}+L_{3}\right)-R}{L_{48}} e^{L_{35}}\right)-\frac{L_{69}}{L_{49}}\left(\left(1-\frac{2\left(L_{2}+L_{4}\right)-R}{L_{49}}\right) e^{L_{2}+L_{4}}+\frac{2\left(L_{2}+L_{4}\right)-R}{L_{49}} e^{L_{35}}\right)-\frac{L_{70}}{L_{50}}((1 \\
& \left.\left.-\frac{2\left(L_{1}+L_{4}\right)-R}{L_{50}}\right) e^{L_{1}+L_{4}}+\frac{2\left(L_{1}+L_{4}\right)-R}{L_{50}} e^{L_{35}}\right)-\frac{L_{71}}{L_{51}}\left(\left(1-\frac{2\left(L_{2}+L_{5}\right)-R}{L_{51}}\right) e^{L_{2}+L_{5}}+\frac{2\left(L_{2}+L_{5}\right)-R}{L_{51}} e^{L_{35}}\right) \\
& -\frac{L_{72}}{L_{52}}\left(\left(1-\frac{2\left(L_{1}+L_{5}\right)-R}{L_{52}}\right) e^{L_{1}+L_{5}}+\frac{2\left(L_{1}+L_{5}\right)-R}{L_{52}} e^{L_{35}}\right)-\frac{L_{73}}{L_{53}}\left(\left(1-\frac{2\left(L_{2}+L_{6}\right)-R}{L_{53}}\right) e^{L_{2}+L_{6}}\right. \\
& \left.\left.+\frac{2\left(L_{2}+L_{6}\right)-R}{L_{53}} e^{L_{35}}\right)-\frac{L_{74}}{L_{54}}\left(\left(1-\frac{2\left(L_{1}+L_{6}\right)-R}{L_{54}}\right) e^{L_{1}+L_{6}}+\frac{2\left(L_{1}+L_{6}\right)-R}{L_{54}} e^{L_{35}}\right)\right), \\
& L_{57}=\alpha^{2} R L_{37} L_{35}^{2}, \\
& L_{58}=\alpha^{2} R L_{38} L_{36}^{2} \text {, } \\
& L_{59}=\operatorname{Re}\left(L_{7} L_{32} L_{2}+\alpha^{2} L_{39}\left(L_{2}+L_{3}\right)^{2}+e^{L_{1}}\left(L_{7} L_{33}+\frac{L_{2}}{e^{L_{2}}-e^{L_{1}}}\left(2 \alpha L_{7} L_{2}+L_{11}+L_{19} L_{3}\right)\right)\right), \\
& L_{60}=\operatorname{Re}\left(L_{7} L_{31} L_{1}-\alpha^{2} L_{40}\left(L_{1}+L_{3}\right)^{2}+e^{L_{2}}\left(L_{7} L_{34}-\frac{L_{1}}{e^{L_{2}}-e^{L_{1}}}\left(2 \alpha L_{7} L_{1}+L_{11}+L_{19} L_{3}\right)\right)\right) \text {, } \\
& L_{61}=\operatorname{Re}\left(L_{8} L_{32} L_{2}+\alpha^{2} L_{41}\left(L_{2}+L_{4}\right)^{2}+e^{L_{1}}\left(L_{8} L_{33}+\frac{L_{2}}{e^{L_{2}}-e^{L_{1}}}\left(2 \alpha L_{8} L_{2}+L_{12}+L_{20} L_{4}\right)\right)\right) \text {, }
\end{aligned}
$$




$$
\begin{aligned}
& L_{62}=\operatorname{Re}\left(L_{8} L_{31} L_{1}-\alpha^{2} L_{42}\left(L_{1}+L_{3}\right)^{2}+e^{L_{2}}\left(L_{8} L_{34}-\frac{L_{1}}{e^{L_{2}}-e^{L_{1}}}\left(2 \alpha L_{8} L_{1}+L_{12}+L_{20} L_{4}\right)\right)\right), \\
& L_{63}=\operatorname{Re}\left(L_{9} L_{32} L_{2}+\alpha^{2} L_{43}\left(L_{2}+L_{5}\right)^{2}+e^{L_{1}}\left(L_{9} L_{33}+\frac{L_{2}}{e^{L_{2}}-e^{L_{1}}}\left(2 \alpha L_{9} L_{2}+L_{13}+L_{21} L_{5}\right)\right)\right) \text {, } \\
& L_{64}=\operatorname{Re}\left(L_{9} L_{31} L_{1}-\alpha^{2} L_{44}\left(L_{1}+L_{5}\right)^{2}+e^{L_{2}}\left(L_{9} L_{34}-\frac{L_{1}}{e^{L_{2}}-e^{L_{1}}}\left(2 \alpha L_{9} L_{1}+L_{13}+L_{21} L_{5}\right)\right)\right) \text {, } \\
& L_{65}=\operatorname{Re}\left(L_{10} L_{32} L_{2}+\alpha^{2} L_{45}\left(L_{2}+L_{6}\right)^{2}+e^{L_{1}}\left(L_{10} L_{33}+\frac{L_{2}}{e^{L_{2}}-e^{L_{1}}}\left(2 \alpha L_{10} L_{2}+L_{14}+L_{22} L_{6}\right)\right)\right) \text {, } \\
& L_{66}=\operatorname{Re}\left(L_{10} L_{31} L_{1}-\alpha^{2} L_{46}\left(L_{1}+L_{6}\right)^{2}+e^{L_{2}}\left(L_{10} L_{34}-\frac{L_{1}}{e^{L_{2}}-e^{L_{1}}}\left(2 \alpha L_{10} L_{1}+L_{14}+L_{22} L_{6}\right)\right)\right) \text {, } \\
& L_{67}=\operatorname{Re} L_{2}\left(L_{7} L_{33}+\frac{L_{15}}{e^{L_{2}}-e^{L_{1}}}\right) e^{L_{1}}, \\
& L_{68}=\operatorname{Re} L_{1}\left(L_{7} L_{34}-\frac{L_{15}}{e^{L_{2}}-e^{L_{1}}}\right) e^{L_{2}}, \\
& L_{69}=\operatorname{Re} L_{2}\left(L_{8} L_{33}+\frac{L_{16}}{e^{L_{2}}-e^{L_{1}}}\right) e^{L_{1}}, \\
& L_{70}=\operatorname{Re} L_{1}\left(L_{8} L_{34}-\frac{L_{16}}{e^{L_{2}}-e^{L_{1}}}\right) e^{L_{2}}, \\
& L_{71}=\operatorname{Re} L_{2}\left(L_{9} L_{33}+\frac{L_{17}}{e^{L_{2}}-e^{L_{1}}}\right) e^{L_{1}}, \\
& L_{72}=\operatorname{Re} L_{1}\left(L_{9} L_{34}-\frac{L_{17}}{e^{L_{2}}-e^{L_{1}}}\right) e^{L_{2}}, \\
& L_{73}=\operatorname{Re} L_{2}\left(L_{10} L_{33}+\frac{L_{18}}{e^{L_{2}}-e^{L_{1}}}\right) e^{L_{1}}, \\
& L_{74}=\operatorname{Re} L_{1}\left(L_{10} L_{34}-\frac{L_{18}}{e^{L_{2}}-e^{L_{1}}}\right) e^{L_{2}},
\end{aligned}
$$

\section{Conflicts of Interest}

The authors declare that there are no conflicts of interest regarding the publication of this paper.

\section{References}

[1] G. N. V. Lachmann, Boundary Layer and Flow Control, Its Principles and Application, vol. 1-2, Pergamon Press, 1961.

[2] K. Gersten and J. F. Gross, "Flow and heat transfer along a plane wall with periodic suction," Zeitschrift für angewandte Mathematik und Physik, vol. 25, no. 3, pp. 399-408, 1974.

[3] K. D. Singh, "Three-dimensional Couette flow with transpiration cooling," Zeitschrift fur Angewandte Mathematik und Physik, vol. 50, no. 4, pp. 661-668, 1999.

[4] R. C. Chaudhary, M. C. Goyal, and U. Gupta, "Threedimensional Couette flow with transpiration cooling between two horizontal parallel porous plates," J. Mech. Cont. \& Maths. Sci, vol. 2, no. 1, pp. 46-58, 2007.

[5] M. Guria and R. N. Jana, "Three-dimensional fluctuating Couette flow through the porous plates with heat transfer," International Journal of Mathematics and Mathematical Sciences, vol. 2006, Article ID 61023, 18 pages, 2006.
[6] B. K. Sharma, M. Agarwal, and R. C. Chaudhary, "Radiation effect on temperature distribution in three-dimensional Couette flow with suction or injection," Applied Mathematics and Mechanics (English Edition), vol. 28, no. 3, pp. 309-316, 2007.

[7] D. S. Chauhan and V. Kumar, "Heat transfer effects in a couette flow through a composite channel partly filled by a porous medium with a transverse sinusoidal injection velocity and heat source," Thermal Science, vol. 15, supplement 2, pp. S175-S186, 2011.

[8] H. Schlichting, Boundary Layer Theory, McGraw-Hill, 1968.

[9] P. Singh, J. K. Sharma, Misra, and K. A. Narayan, "Threedimensional convective flow and heat transfer in a porous medium," Indian Journal of Pure and Applied Mathematics, vol. 19, no. 11, pp. 1130-1135, 1988.

[10] N. Ahmed and D. Sarma, "Three dimensional free convective flow and heat transfer through a porous medium," Indian Journal of Pure and Applied Mathematics, vol. 28, no. 10, pp. 1345-1353, 1997.

[11] M. Guria and R. N. Jana, "Hydrodynamic effect on the threedimensional flow past a vertical porous plate," International Journal of Mathematics and Mathematical Sciences, vol. 2005, no. 20, pp. 3359-3372, 2005.

[12] S. S. Das, "Effect of constant suction and injection on MHD three dimensional couette flow and heat transfer through a 
porous medium," Journal of Naval Architecture and Marine Engineering, vol. 6, no. 1, pp. 41-51, 2009.

[13] P. K. Sharma and R. C. Chaudhary, "Magnetohydrodynamics effect on three-dimensional viscous incompressible flow between two horizontal parallel porous plates and heat transfer with periodic injection/suction," International Journal of Mathematics and Mathematical Sciences, vol. 2004, no. 62, pp. 33573368, 2004.

[14] M. Goyal and N. Naraniya, "MHD three dimensional free convection Couette flow with transpiration cooling," International Journal of Science and Research (IJSR), Index Copernicus Value, vol. 6, article 14, 2013.

[15] L. Sreekala and E. K. Reddy, "Steady MHD Couette flow of an incompresseble viscous fluid through a porous medium between two infinite parallel plates under effect of inclined magnetic field," The International Journal of Engineering and Science (IJES), vol. 3, no. 9, pp. 18-37, 2014.

[16] A. Idowu and J. Olabode, "Unsteady MHD poiseuille flow between two infinite parallel plates in an inclined magnetic field with heat transfer," IOSR Journal of Mathematics, vol. 10, no. 3 , pp. 47-53, 2014.

[17] K. Sumathi, T. Arunachalam, and N. Radha, "Effect of magnetic field on three dimensional fluctuating couette slip flow past porous plates," Applied Mathematical Sciences, vol. 8, no. 177-180, pp. 8809-8821, 2014.

[18] M. Shoaib, M. A. Rana, and A. M. Siddiqui, "Three dimensional flow of upper convected Maxwell fluid along an infinite plane wall with periodic suction," Journal of Computational and Theoretical Nano science, vol. 13, no. 8, pp. 5247-5253, 2016.

[19] M. Shoaib, M. A. Rana, A. M. Siddiqui, and M. Darus, "Threedimensional magnetohydrodynamics flow of upper convected Maxwell fluid along an infinite plane wall with periodic suction," Journal of Computational and Theoretical Nanoscience, vol. 13, no. 11, pp. 8274-8282, 2016.

[20] M. Shoaib, A. M. Siddiqui, M. A. Rana, and M. Imran, "Threedimensional flow of a second grade fluid along an infinite horizontal plane wall with periodic suction," Research Journal for Engineering, Technology, and Sciences (ASRJETS), vol. 18, no. 1, pp. 153-170, 2016.

[21] M. Shoaib, M. A. Rana, and A. M. Siddiqui, "The effect of slip condition on the three-dimensional flow of Jeffrey fluid along a plane wall with periodic suction," Journal of the Brazilian Society of Mechanical Sciences and Engineering, 2017.

[22] A. M. Siddiqui, M. Shoaib, and M. A. Rana, "Three-dimensional flow of Jeffrey fluid along an infinite plane wall with periodic suction," Meccanica, 2017. 


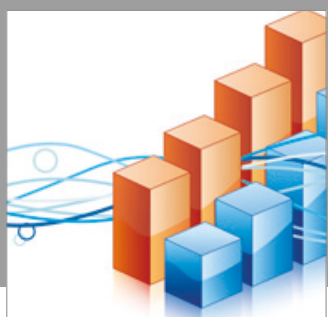

Advances in

Operations Research

vatersals

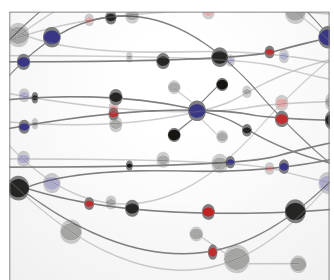

\section{The Scientific} World Journal
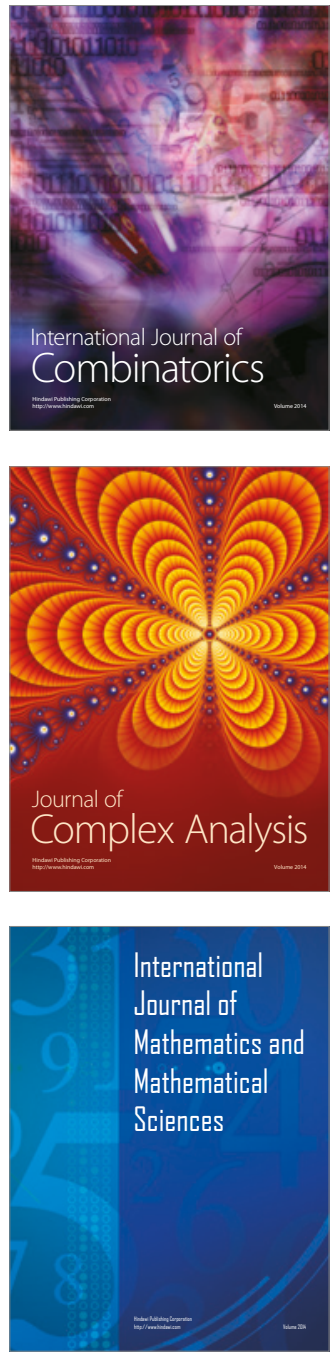
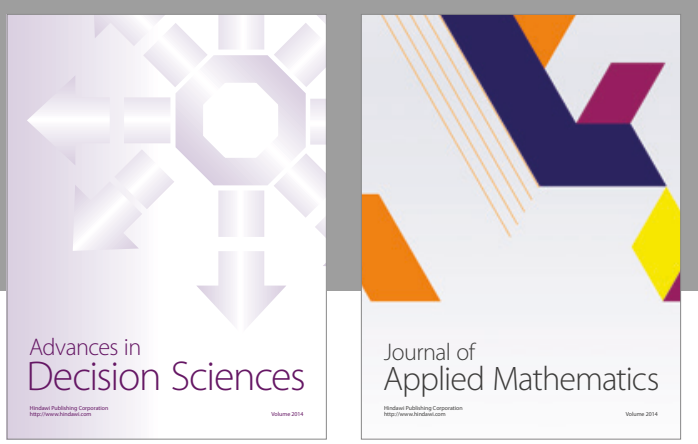

Algebra

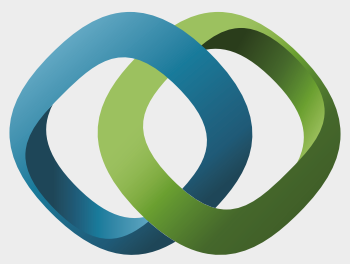

\section{Hindawi}

Submit your manuscripts at

https://www.hindawi.com
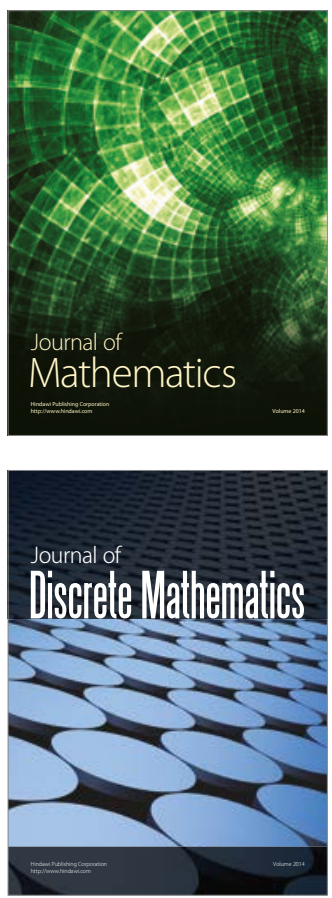

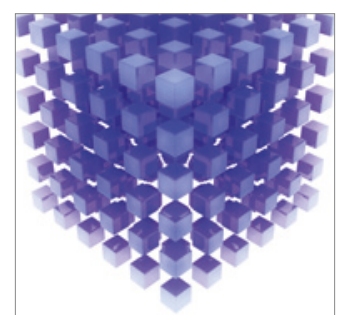

Mathematical Problems in Engineering
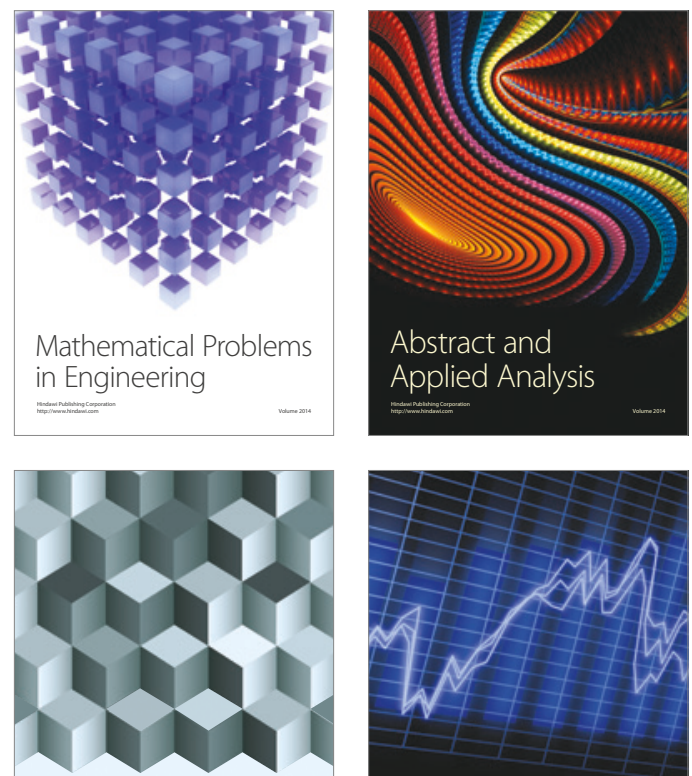

Journal of

Function Spaces

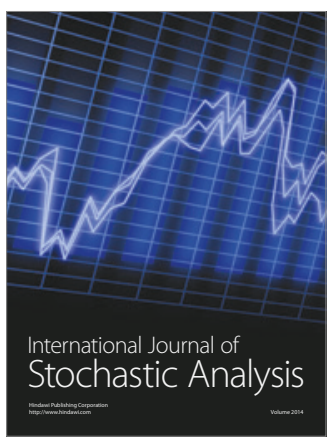

Probability and Statistics
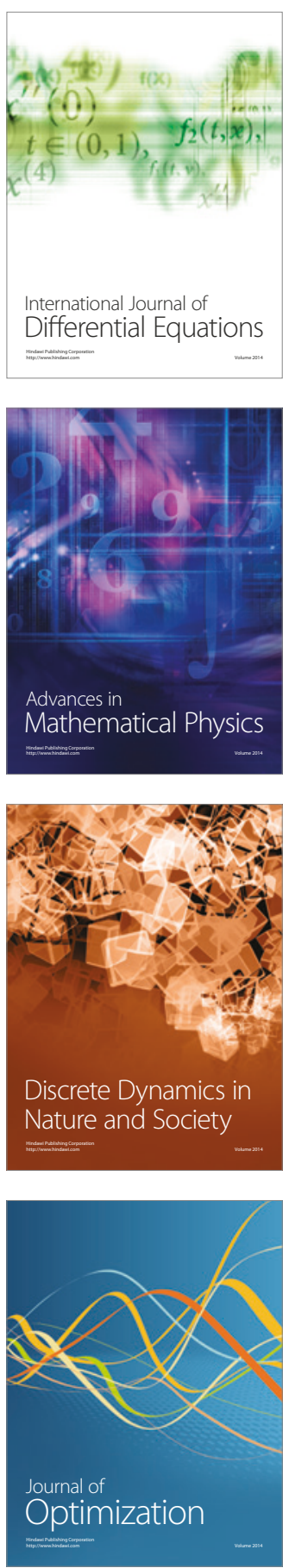